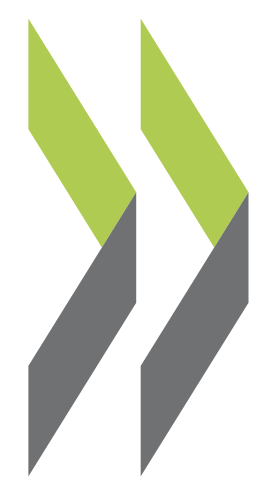

OECD Economics Department Working Papers No. 1154

\title{
Productivity Measurement with Natural Capital and Bad Outputs
}

\section{Nicola Brandt, \\ Paul Schreyer, \\ Vera Zipperer}


Organisation de Coopération et de Développement Économiques

Organisation for Economic Co-operation and Development

24-Jul-2014

ECONOMICS DEPARTMENT

English - Or. English

PRODUCTIVITY MEASUREMENT WITH NATURAL CAPITAL AND BAD OUTPUTS

ECONOMICS DEPARTMENT WORKING PAPERS No. 1154

By Nicola Brandt, Paul Schreyer and Vera Zipperer

OECD Working Papers should not be reported as representing the official views of the OECD or of its member countries. The opinions expressed and arguments employed are those of the author(s).

Authorised for publication by Alvaro Pereira, Director, Country Studies Branch, Economics Department.

All Economics Department Working Papers are available through OECD's Internet website at http://www.oecd.org/eco/workingpapers

JT03360686

Complete document available on OLIS in its original format

This document and any map included herein are without prejudice to the status of or sovereignty over any territory, to the delimitation of international frontiers and boundaries and to the name of any territory, city or area. 
$\mathrm{ECO} / \mathrm{WKP}(2014) 50$

OECD Working Papers should not be reported as representing the official views of the OECD or of its member countries. The opinions expressed and arguments employed are those of the author(s).

Working Papers describe preliminary results or research in progress by the authors and are published to stimulate discussion on a broad range of issues on which the OECD works.

Comments on Working Papers are welcomed, and may be sent to OECD Economics Department, 2 rue André-Pascal, 75775 Paris Cedex 16, France, or by e-mail to eco.contact@oecd.org

This document and any map included herein are without prejudice to the status of or sovereignty over any territory, to the delimitation of international frontiers and boundaries and to the name of any territory, city or area.

You can copy, download or print OECD content for your own use, and you can include excerpts from OECD publications, databases and multimedia products in your own documents, presentations, blogs, websites and teaching materials, provided that suitable acknowledgment of OECD as source and copyright owner is given. All requests for commercial use and translation rights should be submitted to rights@oecd.org. 
ECO/WKP(2014)50

\section{Abstract/Résumé \\ Productivity Measurement with Natural Capital and Bad Outputs}

This paper presents a productivity growth measure that explicitly accounts for natural capital as an input factor and for undesirable goods, or "bads", as an output of the production process. The discussion focuses on the extension of productivity measurement for bad outputs and estimates of their shadow prices, while the inclusion of natural capital is discussed in more depth in a companion paper. As bad outputs are the target of environmental policies, a productivity measure that does not take bad outputs into account will underestimate productivity growth, whenever countries devote some inputs to reducing bad outputs, thus improving the environmental impact of their production processes, rather than to increasing the production of goods and services. An adjusted productivity measures is needed in an analysis of the effect of bad outputs on productivity growth as otherwise the effectiveness of environmental policies in promoting production processes that make more efficient use of the environment will be wrongly assessed. Results suggest that the adjustment of the traditional productivity growth measure for bad outputs is small. While this partly hinges on the fact, that due to a lack of more comprehensive data, only a limited set of bad outputs are considered in this paper, namely $\mathrm{CO}_{2}, \mathrm{SO}_{\mathrm{X}}$ and $\mathrm{NO}_{\mathrm{X}}$ emissions, the relatively small adjustment of the traditional productivity growth measure is good news for two reasons. First, it implies that ignoring the bad outputs considered in this paper results in a relatively small bias of productivity measurement, and thus analysis based on traditional measures should be relatively reliable in this regard. Second, it also implies that the acceleration in productivity growth that would help to substantially reduce the bad outputs considered in this paper, without reducing output growth, should be possible to achieve.

JEL classification: D24, O47, Q3, Q52, Q53

Keywords: multi-factor productivity, total factor productivity, green productivity, natural capital stock, emission shadow prices, carbon dioxide emissions, nitrogen oxide emissions, sulphur oxide emissions

\section{Une mesure de productivité avec capital naturel et des produits indésirables}

Ce papier présente une mesure de croissance de la productivité qui inclut explicitement le capital naturel et des produits non-désirables, ou des «bads », comme outputs du processus de production. La discussion se focalise sur l'extension de la mesure de croissance de productivité qui provient des «bad outputs » et sur l'estimation des leurs prix virtuels, alors que l'inclusion du capital naturel est discuté plus en détail dans un autre papier. Une mesure de productivité qui ne prend pas en compte des produits non-désirés est susceptible de sous-estimer la croissance de productivité chaque fois qu'un pays dédie quelques entrants à la réduction de ces produits non-désirables, pour ainsi améliorer l'impact environnemental de ses processus de production, plutôt qu'à la croissance de la production des biens (désirables) et des services. Comme les produits non-désirables sont la cible de la politique environnementale, une analyse de comment celle-ci impacte sur la croissance de productivité requiert une mesure qui inclut les «bad outputs «, comme celle présentée dans ce papier. Sinon, il y a peu d'espoir d'obtenir une évaluation correcte de l'impact des politiques environnementales sur la promotion des processus de production qui utilisent l'environnement avec plus d'efficacité. Les résultats présentés dans ce papier suggèrent que l'ajustement de la mesure traditionnelle de croissance de productivité pour des produits non-désirables est faible. Ceci est en partie dû au fait que, faute d'avoir accès à des donnés plus complètes, les produits non-désirables inclut dans ce papier se limitent aux émissions des dioxydes de carbon $\left(\mathrm{CO}_{2}\right)$, des oxydes de soufre $\left(\mathrm{SO}_{\mathrm{X}}\right)$ et des oxydes d'azote $\left(\mathrm{NO}_{\mathrm{X}}\right)$. Néanmoins, l'ajustement relativement faible de la mesure de croissance de productivité est une bonne nouvelle pour deux raisons. Premièrement, ceci implique qu'ignorer les produits non-désirables considérés dans ce papier mène à un biais de la mesure de croissance de productivité relativement faible et donc les analyses basées sur des mesures traditionnelles de croissance de productivité devraient être assez fiables. Deuxièmement, ce résultat implique aussi que l'accélération de la croissance de productivité qui contribuerait à réduire substantiellement les produits non-désirables considérés dans ce papier, sans pour autant réduire la croissance de la production des biens et des services, devrait être atteignable.

Classification JEL : D24, O47, Q3, Q52, Q53

Mots clès : productivité multifacteurs, productivité globale des facteurs, productivité verte, stock de capital naturel, prix sous-jacents des émissions, émissions dioxydes de carbon, émissions oxydes de soufre, émissions des oxydes d'azote. 


\section{TABLE OF CONTENTS}

PRODUCTIVITY MEASUREMENT WITH NATURAL CAPITAL AND BAD OUTPUTS ..................... 5

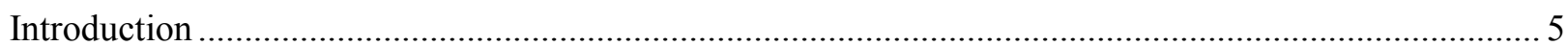

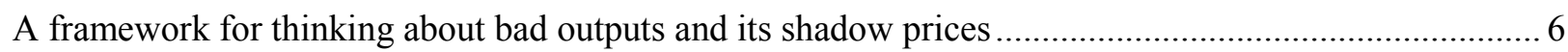

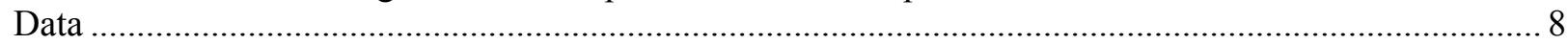

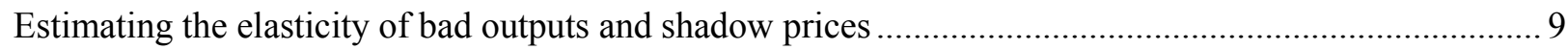

A glance into the literature of estimating shadow prices .................................................................... 10

Estimating the elasticity of good and bad outputs in a general production framework......................... 11

Adjustment of traditional MFP measures for natural capital and emissions .......................................... 12

Costs of further emission reductions in terms of GDP - A simulation exercise ...................................... 17

Shadow prices implied by the estimated elasticities of bad outputs....................................................... 20

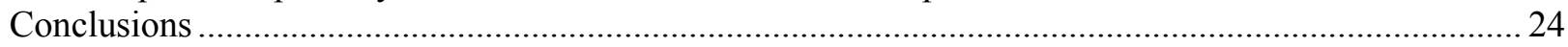

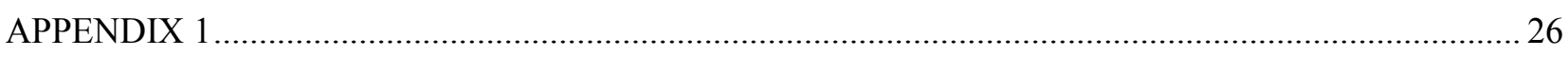

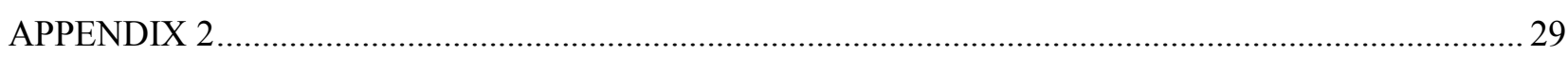

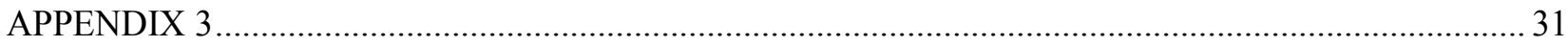

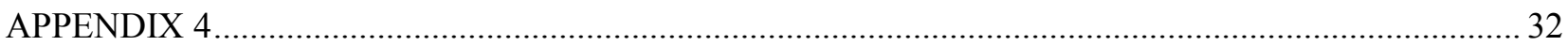

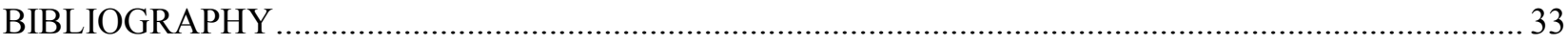

\section{Tables}

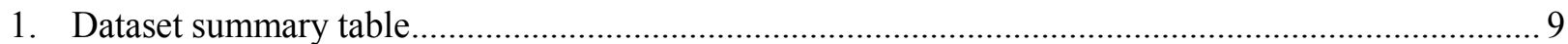

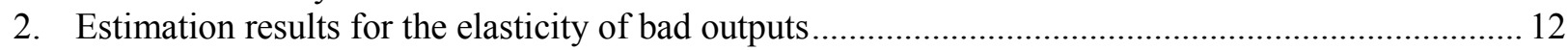

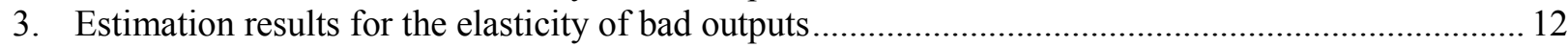

\section{Figures}

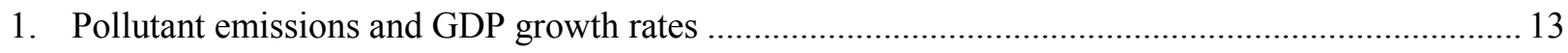

2. Contributions to productivity adjustment of individual pollutants ................................................... 14

3. MFP growth adjustment for $\mathrm{CO} 2$, SOX and NOX with 95\%-confidence interval .......................... 15

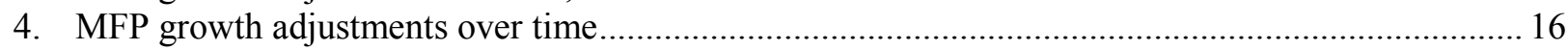

5. Simulated adjustment in GDP or productivity growth to bring $\mathrm{CO} 2$ emissions to

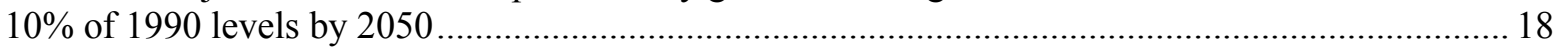

6. Simulated adjustment in GDP or productivity growth to bring SOX emissions to $10 \%$ of 1990 levels 19

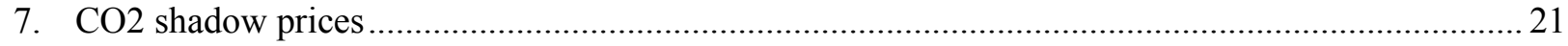

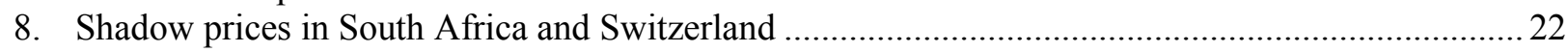

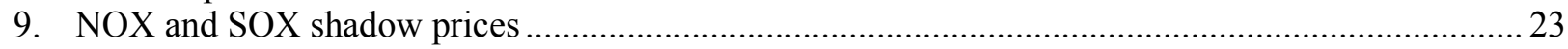


ECO/WKP(2014)50

\title{
PRODUCTIVITY MEASUREMENT WITH NATURAL CAPITAL AND BAD OUTPUTS
}

\author{
by \\ Nicola Brandt, Paul Schreyer and Vera Zipperer ${ }^{1 .}$
}

\section{Introduction}

1. Common measures of economic performance often do not account for the role of the environment in production. While income generated through the depletion of natural capital, including e.g. minerals and fossil fuels, is captured in Gross Domestic Product (GDP), the role of natural capital as a factor input is generally ignored in traditional Multi-Factor Productivity (MFP) growth measures. This is because the underlying production function generally includes labour and produced capital as input factors, but not natural capital, although the extraction of subsoil assets contributes an important share to GDP in some countries. Neither MFP nor GDP capture the damage created through by-products of the production process, such as greenhouse gas emissions leading to climate change or pollution threatening human health and the environment.

2. Based on aggregate country data for OECD countries and for Russia and South Africa, this paper presents an adjustment of traditional MFP growth measurement to capture the role of the environment. The traditional MFP and growth accounting framework is extended in two ways. First, natural capital is included as an input factor, facilitating the analysis of the role of natural capital for GDP and productivity growth. This aspect is discussed in more detail in a companion paper (Brandt et al. 2013). This paper concentrates on a second aspect, namely the recognition of emissions as undesired by-products of the production of goods and services. Emissions of sulphur oxides $\left(\mathrm{SO}_{\mathrm{X}}\right)$ and nitrogen oxides $\left(\mathrm{NO}_{\mathrm{X}}\right)$, as well as carbon dioxide emissions $\left(\mathrm{CO}_{2}\right)$ are included into measurement as such undesirable "bad" outputs.

3. Conceptually, this extension of productivity measurement allows for a more accurate assessment of economic performance. Productivity growth can easily be overestimated in countries where output growth relies to a large extent on the depletion of natural capital. This can lead to an overly optimistic assessment of economic potential and growth in the long run. A similar argument applies to countries that hold production costs down by relying on heavily polluting technologies. While this can generate additional output of goods and services in the short run, it also leads to higher external costs, which can impinge on well-being and the sustainability of economic development. Conversely, the economic performance and sustainability of an economy that invests in a more efficient use of the environment in production may be underestimated, as some inputs do not serve to increase the current production of goods and services, but to reduce the associated negative externalities, improving human health, the integrity of the environment and climate stability. Therefore, when measuring productivity, it can be interesting to consider as outputs not only the goods and services summarised in GDP but to also include externalities, or "bad" outputs, such as air pollution and $\mathrm{CO}_{2}$ emissions.

1. Nicola Brandt and Vera Zipperer are members of the Economics Department of the OECD. Paul Schreyer is a member of the Statistics Directorate of the OECD. The authors owe thanks to Francisco M. Guillen from the Instituto Nacional de Estadistica y Geografia of Mexico for providing data on produced capital stocks for Mexico and Ilya B. Voskoboynikov for providing productivity data for Russia. The authors would like to thank Ivan Haščič, Cyrille Schwellnus, Mauro Pisu, Nils Axel Braathen, Fabrice Murtin and various participants of OECD seminars for their valuable comments and suggestions. The opinions expressed herein are those of the authors and do not necessarily reflect the opinions of the OECD. This research has been possible thanks to generous financial support from the Norwegian Government. 
4. As a by-product of the analysis, this paper also presents implicit shadow prices of $\mathrm{CO}_{2}, \mathrm{NO}_{\mathrm{X}}$ and $\mathrm{SO}_{\mathrm{X}}$ emissions. These can be inferred from estimated elasticities of bad outputs with respect to the function describing the production technology. Shadow price estimates are presented, as they represent interesting information by themselves and they can serve as a reality check for the estimates of transformation elasticities. Shadow price estimates correspond to the (marginal) cost for producers of complying with regulations constraining the output of emissions or pollutants, in terms of the value of foregone goods and services that could otherwise have been produced. These shadow prices can be interpreted as reflecting the overall stringency of environmental regulations concerning the corresponding bad outputs.

5. This paper is structured as follows. Section 2 describes a production technology that transforms inputs into good and bad outputs and derives a productivity growth measure. The data is described in section 3. Estimates of the elasticity of bad outputs are presented in section 4. Section 5 compares the extended productivity growth measure with the traditional MFP growth measure along with a sensitivity analysis and presents results. Section 6 discusses the implicit shadow prices resulting from the estimation of elasticities of bad outputs. Section 7 concludes and gives directions for further research.

\section{A framework for thinking about bad outputs and its shadow prices}

6. Consider a transformation curve, that describes the maximum amount of good outputs, $\mathrm{Y}$, and bad outputs, $\mathrm{R},(Y, R) \in R_{+}^{N}$, that can be obtained by using input vector $\mathrm{X} \in R_{+}^{M}$

$H(Y, R, X, t)=1$

where $t$ is an index of time. Following the framework laid-out in the companion paper Brandt et al. (2013), the input vector $X$ consists of labour, produced capital and natural capital, $X=(L, K, S) . H$ thus describes combinations of outputs and inputs that can be observed when production is efficient. $\mathrm{H}$ is non-decreasing in inputs and bad outputs and non-increasing in good outputs: $H_{Y} \leq 0 ; H_{R}, H_{X} \geq 0$. This implies that more good output can be produced only by accepting more bad output: $\frac{d Y}{d R}=-\frac{H_{R}}{H_{Y}}>0$ (see Appendix 1) or conversely, bad outputs can only be reduced by accepting less output of goods and services.

7. The logarithmic derivative of the transformation function with respect to time, which can be interpreted as technological progress or total factor productivity growth, equals the sum of weighted outputs less the sum of weighted inputs.

$\frac{d \ln H}{d t}=-\sum_{i} \varepsilon_{H Y_{i}} \frac{d \ln Y_{i}}{d t}-\sum_{i} \varepsilon_{H R_{i}} \frac{d \ln R_{i}}{d t}-\sum_{i} \varepsilon_{H X_{i}} \frac{d \ln X_{i}}{d t}$

where outputs and inputs are weighted with their elasticity with respect to the transformation function (Appendix 1). To the extent that weighted growth of good outputs exceeds the weighted growth of inputs and of bad outputs there is positive productivity growth, given the sign of the elasticities, which is negative for good outputs and positive for bad outputs as well as inputs: $\varepsilon_{H Y_{i}}<0$ and $\varepsilon_{H R_{i}}, \varepsilon_{H X_{i}}>0$.

8. For the interpretation of the results presented in this paper, it is useful to take a look at what equation (2) implies for the role of bad outputs. Starting from a steady state growth path, where all inputs and outputs as well as productivity grow at a constant rate, lower growth in bad outputs can only be achieved if inputs or productivity grow faster or if good outputs grow more slowly. The required change in the growth rate of inputs, good outputs or productivity will be lower, the lower the elasticity of bad outputs. This means that a reduction in bad output growth is easier to achieve or less costly in terms of foregone good output growth if the elasticity of bad outputs is relatively low. New technologies that allow producers to reduce weighted bad output growth more than weighted good output growth, lead to an increase in productivity growth. This can be considered as positive environmental technological change. 
9. For the discussion in this paper it is also useful to note that the weights of outputs or their elasticities are equivalent to their value shares, while the elasticities of inputs and thus their weights in productivity measurement are equivalent to cost shares when producers maximise profits (minimise costs) (see equation (3)). Prices of bad outputs are negative and correspond to the marginal abatement cost of emissions in terms of foregone revenues from good output that would result if one further unit of emissions had to be avoided (Appendix 1). In that sense, the relevant price for emissions in a productivity framework is the marginal cost facing producers to achieve the abatement required by different policies constraining emissions.

$\frac{d \ln H}{d t}=\sum \frac{P_{Y i} Y_{i}}{\rho} \frac{d \ln Y_{i}}{d t}+\sum \frac{P_{R i} R_{i}}{\rho} \frac{d \ln R_{i}}{d t}-\sum_{i} \frac{P_{X i} X_{i}}{\gamma} \frac{d \ln X_{i}}{d t}$

where $\rho=\sum \mathrm{P}_{\mathrm{Yi}} \mathrm{Y}_{\mathrm{i}}+\sum \mathrm{P}_{\mathrm{Ri}} \mathrm{R}_{\mathrm{i}}$ is the total value of good and bad outputs and $\gamma=\sum \mathrm{P}_{\mathrm{Xi}} \mathrm{X}_{\mathrm{i}}$ are total input costs. In this study, $\mathrm{R}=\left(\mathrm{R}_{1}, \mathrm{R}_{2}, \mathrm{R}_{3}\right)$ includes $\mathrm{CO}_{2}, \mathrm{NO}_{\mathrm{X}}$ and $\mathrm{SO}_{\mathrm{X}}$ emissions. Inputs considered are labour, $\mathrm{L}$, along with services from produced capital, $\mathrm{K}$, and the flow of services from the natural capital stock, $\mathrm{S}$, which is an extension of the traditional Solow residual framework. If all prices of inputs and outputs were known, the productivity measure described in (3) could be calculated by using output value and input cost shares, which could be relatively easily measured with the available data. Yet, for bad outputs prices can rarely be observed, unless there is an emissions trading system or tax. While such trading systems or taxes exist in some countries, they generally do not cover all emissions in the economy. To infer weights for bad outputs, their elasticities are econometrically estimated in this paper.

10. To compare the traditional MFP measure - often referred to as the Solow residual - with the extended measure proposed in this paper it is useful to remember first that the traditional MFP growth measure is a special case of (3) with only one good output, GDP, no bad outputs along with labour and (produced) physical capital as inputs.

$\frac{\mathrm{d} \ln M F P}{\mathrm{dt}} \equiv \frac{\mathrm{dln} \mathrm{H}^{\mathrm{T}}}{\mathrm{dt}}=\frac{\mathrm{d} \ln \mathrm{Y}}{\mathrm{dt}}-\left(\frac{\mathrm{wL}}{\gamma^{\prime}} \frac{\mathrm{dln} \mathrm{L}}{\mathrm{dt}}+\frac{\mathrm{u}_{\mathrm{K}} \mathrm{K}}{\gamma^{\prime}} \frac{\mathrm{dln} \mathrm{K}}{\mathrm{dt}}\right)=\frac{\mathrm{d} \ln \mathrm{Y}}{\mathrm{dt}}-\frac{\mathrm{dln} \mathrm{Z}}{\mathrm{dt}}$

where the suffix $\mathrm{T}$ is used to make clear that this is a special case of the more general transformation function with only one (good) output and two inputs. The wage rate is denoted by $\mathrm{w}, \mathrm{u}_{\mathrm{K}}$ is the user cost of produced capital. Note that the weight of the good output becomes 1 , when there are no other good or bad outputs. Total resource costs are defined by $\gamma^{\prime} \equiv \mathrm{wL}+\mathrm{u}_{\mathrm{K}} \mathrm{K}$. The shorthand $\frac{\mathrm{d} \operatorname{lnZ}}{\mathrm{dt}}$ is used to capture the combined rate of growth of inputs, each weighted by its share in costs. In the extended framework, which includes the flow of services from the natural capital stock, $\mathrm{S}$, costs are considered to be larger, including also the costs of services from natural capital $\gamma \equiv w L+u_{K} K+\sum_{i} u_{S_{i}} S_{i}$. $u_{S}$ is the user cost of natural capital, which for non-renewable resources can be shown to correspond to the unit rent under profitmaximising extraction over time. The cost shares of both labour and capital will have to be scaled down to reflect the increase in total costs, when the traditional measure is adjusted to include natural capital.

11. The traditional Solow residual and the extended productivity growth measure presented in this paper, which is referred to as green multi-factor productivity growth (GMFP), compare as follows (see Appendix 2 for derivation and Brandt et al. (2013) for more conceptual details on the input side):

GMFP growth for countries for which user cost of capital is measured directly:

$\frac{\mathrm{d} \operatorname{lnGMFP}}{\mathrm{dt}} \equiv \frac{\mathrm{dln} \mathrm{H}}{\mathrm{dt}}=\frac{\mathrm{d} \ln M F P}{\mathrm{dt}}+\frac{\mathrm{u}_{\mathrm{S}} \mathrm{S}}{\gamma}\left(\frac{\mathrm{dlnZ}}{\mathrm{dt}}-\frac{\mathrm{d} \ln S}{\mathrm{dt}}\right)-\frac{\mathrm{P}_{\mathrm{R}} \mathrm{R}}{\rho}\left(\frac{\mathrm{dln} \mathrm{Y}}{\mathrm{dt}}-\frac{\mathrm{dlnR}}{\mathrm{dt}}\right)$ 
GMFP growth for countries where user cost of capital is calculated as a residual:

$\frac{\mathrm{dlnGMFP}}{\mathrm{dt}} \equiv \frac{\mathrm{d} \ln \mathrm{H}}{\mathrm{dt}}=\frac{\mathrm{d} \ln M F P}{\mathrm{dt}}+\frac{\mathrm{u}_{\mathrm{S}} \mathrm{S}}{\mathrm{P}_{\mathrm{Y}} \mathrm{Y}}\left(\frac{\mathrm{d} \ln \mathrm{K}}{\mathrm{dt}}-\frac{\mathrm{dln} S}{\mathrm{dt}}\right)-\frac{\mathrm{P}_{\mathrm{R}} \mathrm{R}}{\rho}\left(\frac{\mathrm{dln} \mathrm{Y}}{\mathrm{dt}}-\frac{\mathrm{dlnR}}{\mathrm{dt}}\right)$

Where $\mathrm{R}$ should be viewed as an aggregate of different types of emissions $\mathrm{R}_{\mathrm{i}}(\mathrm{i}=1,2, \ldots)$, much like GDP is a composite measure of different goods and services.

12. As shown in Appendix 2 and discussed in more detail in Brandt et al. (2013), the difference between productivity growth as measured by the Solow residual and green MFP will vary, depending on how the cost of produced capital is measured in the Solow residual framework. If the cost share of produced capital is measured by relying on a direct estimate of the user cost of capital, then the difference between traditional and green MFP depends on the weighted difference between the growth rates of labour and produced physical capital, on the one hand, and the growth rate of the natural capital services used in production on the other hand (equation (5)). If the cost of capital is instead measured as the residual between GDP and aggregate wage costs, a measurement which relies on the assumptions of perfect competition and constant returns to scale, then the difference in the growth rate of traditional and green MFP depends on the weighted difference between the growth rates of produced physical capital, on the one hand, and natural capital services, on the other hand (equation (6)).

13. The adjustment is negative if natural capital has grown faster than the other inputs (labour and produced capital) as in equation (5) or faster than produced capital as in equation (6), respectively. The interpretation is that the input index fails to take into account a fast growing input, thus underestimating aggregate factor input growth. Since productivity growth is output growth less inputs growth, underestimating input growth is equivalent to overestimating productivity growth.

14. The adjustment of the traditional MFP growth measure as a result of the inclusion of bad outputs depends on the difference in growth rates of good and bad outputs weighted by the elasticity of bad outputs. Note that the adjustment for bad outputs is positive when good outputs grow faster than bad outputs, because $\mathrm{P}_{\mathrm{R}}<0$.

\section{Data}

15. Our analysis is conducted with aggregate economy data for a sample of OECD countries along with Russia and South Africa (Table 1). Where data are available, we use the OECD Productivity Database to retrieve MFP growth and costs estimates, as well as input and output data. The user cost of capital is estimated directly in this database, drawing on its elements, namely the price of investment goods and its rate of change, an estimate of the depreciation rate and of the long run rate of return. For a detailed description of the Productivity Database and methodology see OECD (2001) and the corresponding website $^{2}$. National data sources are used for a range of countries, for which no data are available in the Productivity Database that is for Chile, Mexico, Russia and South Africa. For these countries, constant returns to scale to capital and labour are assumed and the cost share of capital is estimated as the residual after deducting wage costs from GDP. The timeframe of the analysis is $1990-2008$ for most countries and shorter for those where consistent data were not available over the whole period. Table 1 describes the dataset in more detail.

16. We extend the notion of capital, by including the flow of the natural capital inputs used in production, such as minerals, oil, gas and coal. Both the flow of the natural capital inputs and their price,

2. http://www.oecd.org/std/productivitystatistics 
the user cost of natural capital, measured as the unit rent are obtained from the World Bank. For a more detailed discussion of these data and measurement issues see Brandt et al. (2013).

17. Bad outputs included in the empirical implementation are emissions of carbon dioxide $\left(\mathrm{CO}_{2}\right)$, nitrogen oxides $\left(\mathrm{NO}_{\mathrm{X}}\right)$ and sulphur oxides $\left(\mathrm{SO}_{\mathrm{X}}\right)$. These data are taken from the Air and Climate Database of the OECD, supplemented, where necessary, by data on $\mathrm{CO}_{2}$ emissions from the World Bank (for details see Table 1).

Table 1. Dataset summary table

\begin{tabular}{|c|c|c|c|}
\hline Variable & Source & Countries covered & $\begin{array}{l}\text { Time period } \\
\text { covered }\end{array}$ \\
\hline $\begin{array}{l}\text { MFP, labour, capital, } \\
\text { wage and user costs } \\
\text { of capital }\end{array}$ & $\begin{array}{l}\text { OECD } \\
\text { Productivity } \\
\text { database }\end{array}$ & $\begin{array}{l}\text { AUS, AUT, BEL, CAN, CHE, DEU, DNK, ESP, FIN, FRA, } \\
\text { GBR, IRL, ITA, JPN, KOR, NLD, NOR, NZL, PRT, SWE, } \\
\text { USA }\end{array}$ & $1990-2008$ \\
\hline $\begin{array}{l}\text { MFP, labour, capital, } \\
\text { wage and user costs } \\
\text { of capital }\end{array}$ & $\begin{array}{l}\text { National } \\
\text { Source }\end{array}$ & $\mathrm{CHL}^{1)}, \mathrm{MEX}^{21}, \mathrm{RUS}^{31}, \mathrm{ZAF}$ & $1996-2008$ \\
\hline Natural capital data & World Bank & $\begin{array}{l}\text { AUS, AUT, BEL, CAN, CHE, CHL, DEU, DNK, ESP, FIN, } \\
\text { FRA, GBR, IRL, ITA, JPN, KOR, MEX, NLD, NOR, NZL, } \\
\text { PRT, SWE, USA, RUS, ZAF, }\end{array}$ & $1990-2008$ \\
\hline Natural capital rent & World Bank & $\begin{array}{l}\text { AUS, AUT, BEL, CAN, CHE, CHL, DEU, DNK, ESP, FIN, } \\
\text { FRA, GBR, IRL, ITA, JPN, KOR, MEX, NLD, NOR, NZL, } \\
\text { PRT, SWE, USA, RUS, ZAF, CHN, IDN, KHM, MYS, } \\
\text { PHL, THA, VNM }\end{array}$ & $1990-2008$ \\
\hline \multirow[t]{2}{*}{$\mathrm{CO}_{2}$ emissions } & $\begin{array}{l}\text { OECD Air and } \\
\text { Climate } \\
\text { database }\end{array}$ & $\begin{array}{l}\text { AUS, AUT, BEL, CAN, CHE, CHL, DEU, DNK, ESP, FIN, } \\
\text { FRA, GBR, IRL, ITA, JPN, KOR, NLD, NOR, NZL, PRT, } \\
\text { RUS, SWE, USA }\end{array}$ & $1990-2008$ \\
\hline & World Bank & MEX, ZAF, CHN, IDN, KHM, MYS, PHL, THA, VNM & $1990-2008$ \\
\hline SOx emissions & $\begin{array}{l}\text { OECD Air and } \\
\text { Climate } \\
\text { database }\end{array}$ & $\begin{array}{l}\text { AUS, AUT, BEL, CAN, CHE, CHL, DEU, DNK, ESP, FIN, } \\
\text { FRA, GBR, IRL, ITA, JPN, KOR, NLD, NOR, NZL, PRT, } \\
\text { SWE, USA }\end{array}$ & $1990-2008$ \\
\hline NOx emissions & $\begin{array}{l}\text { OECD Air and } \\
\text { Climate } \\
\text { database }\end{array}$ & $\begin{array}{l}\text { AUS, AUT, BEL, CAN, CHE, CHL, DEU, DNK, ESP, FIN, } \\
\text { FRA, GBR, IRL, ITA, JPN, KOR, NLD, NOR, NZL, PRT, } \\
\text { RUS, SWE, USA }\end{array}$ & $1990-2008$ \\
\hline \multicolumn{4}{|c|}{$\begin{array}{ll}1 . & \text { Productivity data for Chile covers } 1997-2008 .\end{array}$} \\
\hline \multicolumn{4}{|c|}{$\begin{array}{l}\text { 2. Productivity data }(1996-2008) \text { are calculated on the basis of a dataset kindly provided by the Instituto Nacional de } \\
\text { Estadistica y Geografia from Mexico. }\end{array}$} \\
\hline \multicolumn{4}{|c|}{$\begin{array}{l}\text { 3. Productivity data for Russia (1996 - 2008) were generously provided by llya B. Voskoboynikov. For more details on the } \\
\text { dataset see the corresponding paper (Voskoboynikov, 2012). }\end{array}$} \\
\hline
\end{tabular}

\section{Estimating the elasticity of bad outputs and shadow prices}

18. The adjustment of traditional productivity measures for bad outputs requires an estimation of or assumptions about either the elasticity of bad outputs or their price. It can be seen from equation (5) and (6) that the calculation of adjusted productivity growth measures is based on the quantification of the elasticity of bad outputs, $\frac{P_{R} R}{\rho}$. This elasticity can be directly estimated as a whole or it can be calculated by making assumptions about the price of bad outputs, $P_{R}$. This price is rarely observable in reality and therefore has to be estimated as shadow price or be attributed a specific monetary value. In order to adjust their estimated productivity growth rates, Vouvaki and Xepapadeas (2008) for example assume a value of $20 \$ / \mathrm{tCO}_{2}$ based on the meta-analysis of Tol (2005) on the social cost of carbon. However, most of the literature on adjusted productivity growth measures tries to avoid such ad hoc assumptions about the price of bad outputs. In the following section, the most relevant literature on the estimation of shadow prices in the context of adjusted productivity growth measures is described, followed by a description of the approach employed in this analysis. 


\section{A glance into the literature of estimating shadow prices}

19. One way to adjust traditional MFP measures to account for the role of externalities would be to estimate their shadow prices and measure the elasticity of bad outputs exploiting the fact that they equal their share in the total value of outputs. Such an approach could build on - a relatively small - literature that estimates such shadow prices, in some cases precisely because the aim is to adjust conventional productivity measures for externalities. Most studies in the literature that estimate shadow prices use a distance function framework pioneered by Färe et al. (1993). A distance function is related to the transformation curve in equation (1) in that they both can describe the same technology (Appendix 1). The difference is that the distance function describes combinations of inputs and outputs that are feasible given the technology, including inefficient combinations in the sense that outputs could be increased given the input vector or inputs could be reduced given the outputs vector. The transformation function, in turn, describes only efficient production in that output vectors resulting from that function cannot be increased without increases in inputs. This is sometimes referred to as the production frontier.

20. A common approach to derive the parameters of a distance function is to apply a linear programming technique pioneered by Aigner Chu (1968). Based on a set of standard assumptions regarding characteristics of the production technology (see Appendix 1 and Färe and Primont, 1995), regularity conditions are derived, with which the distance function has to comply. For example, an output distance function has to be homogeneous in outputs, non-increasing in bad outputs and non-decreasing in good outputs. For a differentiable distance function this implies that its derivatives with respect to good outputs, Y, have to be non-negative and the derivatives with respect to bad outputs, $\mathrm{R}$, and inputs, $\mathrm{X}$, have to be non-positive. These conditions are used as a basis for linear programming. Most researchers use a fairly flexible functional form, often a translog. With the parameters of the distance function, the shadow prices can be recovered thanks to the distance function's dual relationship with the revenue function (Färe et al. 1993). This technique has been used in several contexts in which bad outputs are assumed to be present. Industry studies include pulp and paper (Färe et al., 1993; Hailu and Veeman, 2000), electricity (Coggins and Swinton, 1996; Kwon and Yun, 1999) and agriculture (Rezek and Perrin, 2004) to name some examples.

21. Another option is to use econometric estimation to determine the best-fit distance function based on the assumption that the distance from the frontier is stochastic. This technique better accounts for random or measurement error and allows for hypothesis testing. The disadvantage compared to linear programming is that it is much more challenging to impose inequality restrictions which would ensure that the derivatives of the distance functions have the right sign. This is a particular concern with flexible functional forms. In these cases the derivatives are functions of estimated parameters and data, which can easily lead to large changes in both the size and the sign of derivatives at different data points. This is particularly likely for country panel data that is used in this study, as countries operate at very different scale. Therefore, there are only few examples of studies that have chosen this approach without using econometric techniques that allow for inequality restrictions. One of the very rare examples is Cuesta et al. (2009). Atkinson and Dorfman (2005), in contrast, employ a Bayesian technique to impose inequality, monotonicity and convexity restrictions on their distance function. Rezek and Campbell (2007) use constrained generalized maximum entropy estimation to impose binding inequality restrictions.

22. With the limited number of data points available in the dataset used in this study, it turned out to be impossible to obtain reasonable estimates for a distance function with a flexible functional form. Estimated parameters implied derivatives with respect to outputs that had the wrong sign for at least half of the data points, irrespective of the estimation technique used. It was possible to estimate parameters that were correctly signed and implied reasonable shadow price estimates, when a Cobb-Douglas functional form was imposed. However, the Cobb-Douglas functional form is not well suited for a distance function, as it violates the condition that the distance function has to be convex in outputs. While a Cobb-Douglas 
function could still be viewed as a linear approximation to a more general functional form, it seemed preferable to use a different framework that is general and at the same time parsimonious in parameters that need to be estimated.

\section{Estimating the elasticity of good and bad outputs in a general production framework}

23. A particularly simple approach to retrieve the data necessary for the productivity growth adjustment detailed in equations (5) and (6) would be to estimate the elasticity of bad outputs directly. There are few examples for this in the literature. One of them is Keilbach (1995) who assumes a CobbDouglas form for the production function, which is separable in good and bad outputs. But a more general and even simpler approach is possible by exploiting the fact that the elasticities of the transformation function with respect to inputs equal their cost shares under costs minimisation (profit maximisation). They can thus be measured with data available from national accounts, as detailed above. Measuring the elasticities of inputs directly with data on cost shares reduces the need to estimate parameters to the elasticities of outputs. With the elasticities measured with data or estimated econometrically, an extended productivity measure can be calculated as in equation (3). This approach is general, in that it is not necessary to assume a specific functional form for the transformation function. It is parsimonious in terms of the number of parameters that have to be estimated. Given that the data set used in this paper is relatively small, this is a clear advantage. The estimation framework also directly fits the productivity measure presented in this study. However, this approach relies on the assumption of cost minimisation, as mentioned above.

24. Equation (2) can be re-arranged to estimate the elasticity of good and bad outputs in a relatively straightforward way (see Appendix 3). In particular, if there is only one good output, GDP, as for the data analysed in this paper, and one bad output, equation (2) can be rearranged to read:

$\hat{Y}_{i t}=\frac{\rho}{P_{Y} Y} * \widehat{H}_{i t}+\frac{\rho}{P_{Y} Y} * \hat{Z}_{i t}+\left(1-\frac{\rho}{P_{Y} Y}\right) * \hat{R}_{i t}$

Where $\hat{Z}=\sum_{i} \frac{P_{X j} X_{j}}{\gamma} \widehat{X}_{J}$ is the weighted aggregate growth rate of the factor inputs labour, physical capital and natural capital. Explicitly, the input growth is calculated as $\hat{Z}=\frac{w L}{\gamma} \widehat{L}+\frac{u_{K} K}{\gamma} \widehat{K}+\sum_{i} \frac{u_{S_{i}} S_{i}}{\gamma} \widehat{S_{l}}$ with total costs equal to $\gamma=\mathrm{wL}+\mathrm{u}_{\mathrm{K}} \mathrm{K}+\sum_{\mathrm{i}} \mathrm{u}_{\mathrm{S}_{\mathrm{i}}} \mathrm{S}_{\mathrm{i}}$. The parameters of this equation can be estimated with the following equation:

$\hat{Y}_{i t}=\alpha_{0}+\alpha_{1} * \hat{Z}_{i t}+\alpha_{2} * \hat{R}_{i t}+\varepsilon_{i t}$

where $\alpha_{0}$ is a constant and $\varepsilon$ is an error term.

25. The elasticity of bad outputs can be derived from the estimated parameter $\alpha_{2}$ as (see Appendix 3)

$\varepsilon_{H R_{i}}=\frac{\alpha_{2}}{1-\alpha_{2}}$

26. Equation (8) is estimated with country- and time-fixed effects to account for time-specific shocks and country-specific factors that might be correlated with the error term. The input growth indicator Z includes labour, produced capital and natural capital input growth. In principle, it would be possible to estimate the elasticities for all three bad outputs jointly. However, the three variables are highly collinear, probably not least because many combustion processes lead to $\mathrm{CO}_{2}, \mathrm{SO}_{\mathrm{X}}$ and $\mathrm{NO}_{\mathrm{X}}$ emissions in fairly fixed proportions. Since there is a problem of collinearity, elasticities are estimated separately in this paper. Results are reported in table 3. The sample period covers 1990-2008. There are 25 countries in the sample 
for the estimation for $\mathrm{CO}_{2}$ and fewer for $\mathrm{SO}_{\mathrm{X}}$ and $\mathrm{NO}_{\mathrm{X}}$, as data on $\mathrm{NO}_{\mathrm{X}}$ emissions is lacking for Mexico and South Africa. $\mathrm{SO}_{\mathrm{x}}$ data is lacking for Russia, South Africa and Mexico. Robust standard errors are reported in brackets.

Table 2. Estimation results for the elasticity of bad outputs (equation $8^{1)}$ )

Least squares estimates with country and time dummies

\begin{tabular}{lrrr}
\multicolumn{1}{c}{ Bad output } & $\mathrm{CO}_{2}$ & $\mathrm{SO}_{\mathrm{x}}$ & $\mathrm{NO}$ \\
\hline$\alpha_{1}$ (input index) & 0.94 & 0.98 & 0.94 \\
& $(0.015)$ & $(0.008)$ & $(0.020)$ \\
$\alpha_{2}$ (bad output) & 0.064 & 0.02 & 0.061 \\
& $(0.015)$ & $(0.009)$ & $(0.020)$ \\
F-test (p-value): & 0.32 & 0.09 & 0.36 \\
$\alpha_{2}+\alpha_{1}=1$ & & & 370 \\
No. of observations & 395 & 357 & 370 \\
\hline
\end{tabular}

1. The input growth indicator comprises labour, produced capital and natural capital.

27. Note that equation (3) implies that the sum of $\alpha_{2}$ and $\alpha_{1}$ equals 1 . This condition was imposed on the estimation equation. Overall this restriction is very well supported by the data. The F-test for the hypothesis cannot be rejected at any conventional level of significance for the estimation equations with $\mathrm{NO}_{\mathrm{x}}$ and $\mathrm{CO}_{2}$. For the equation with $\mathrm{SO}_{\mathrm{x}}$ it is marginally rejected at the 10 per cent level of significance, but not at the five per cent level. The respective p-values are shown in table 2 . The implied elasticity of bad outputs, which is calculated as in equation 9, is presented in table 3. Standard errors were computed with the delta method. What is important to note for the interpretation of the extended productivity measure including emissions is that the elasticity is very small when comparing it to the elasticities of traditional input and good outputs. The elasticity of produced capital is above 0.7 for almost all countries in the sample and the elasticity of labour is above 0.2 . The low elasticities of bad outputs also imply that the elasticity of GDP is close to one.

Table 3. Elasticity of bad output

Implied by pooled least squares (table 2)

\begin{tabular}{rrrr} 
Bad output & $\mathrm{CO}_{2}$ & $\mathrm{SO}_{\mathrm{X}}$ & $\mathrm{NO}$ \\
\hline Elasticity $\varepsilon_{H R_{i}}$ & 0.068 & 0.020 & 0.065 \\
& $(0.017)$ & $(0.009)$ & $(0.023)$ \\
\hline
\end{tabular}

1. The input growth indicator comprises labour, produced capital and natural capital.

28. The point estimates for the elasticity for bad outputs from the estimation with fixed effects and time dummies are used to present adjusted MFP growth measures in what follows. The $95 \%$ confidence interval of these estimates serves to conduct sensitivity analyses.

\section{Adjustment of traditional MFP measures for natural capital and emissions}

29. All countries in the sample have achieved technological progress over the past two decades, in that sense that bad outputs grew more slowly than GDP. While $\mathrm{CO}_{2}$ emission growth was positive in most countries, it remained well below GDP growth in all but one case. In nearly every country $\mathrm{SO}_{\mathrm{x}}$ emissions declined (Figure 1). $\mathrm{NO}_{\mathrm{X}}$ emissions declined in a majority of the investigated countries. 
Figure 1. Emissions and GDP growth rates

Average annual growth rates in percentage points, 1991 - 2008

$\mathrm{CO}_{2}$ emissions growth rate

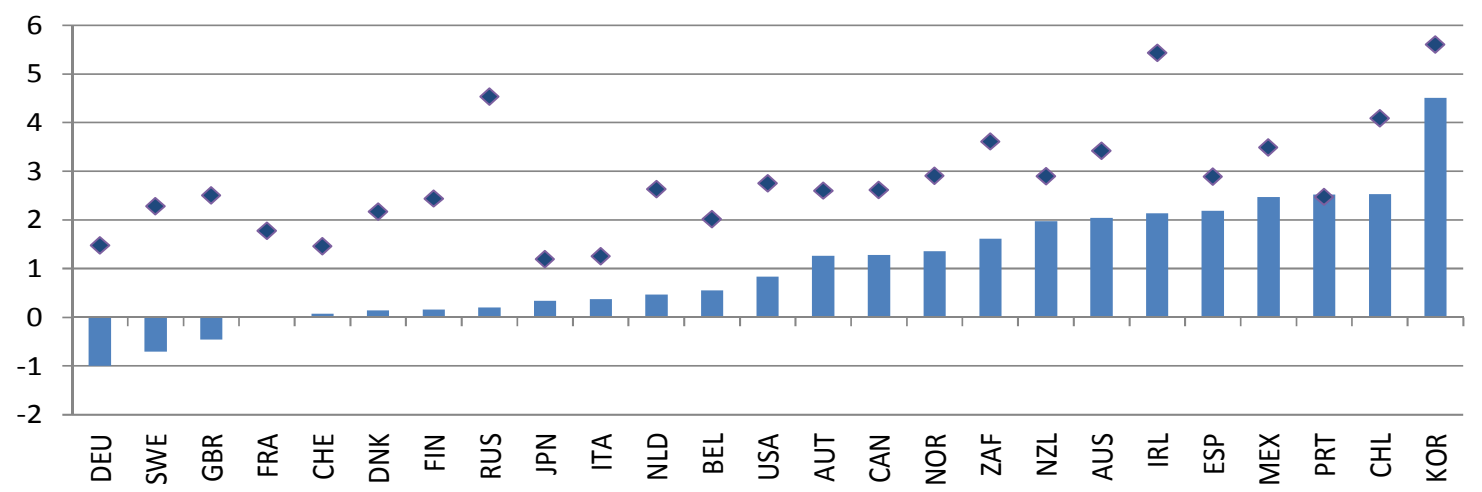

$\mathrm{SO}_{\mathrm{x}}$ emissions growth rate

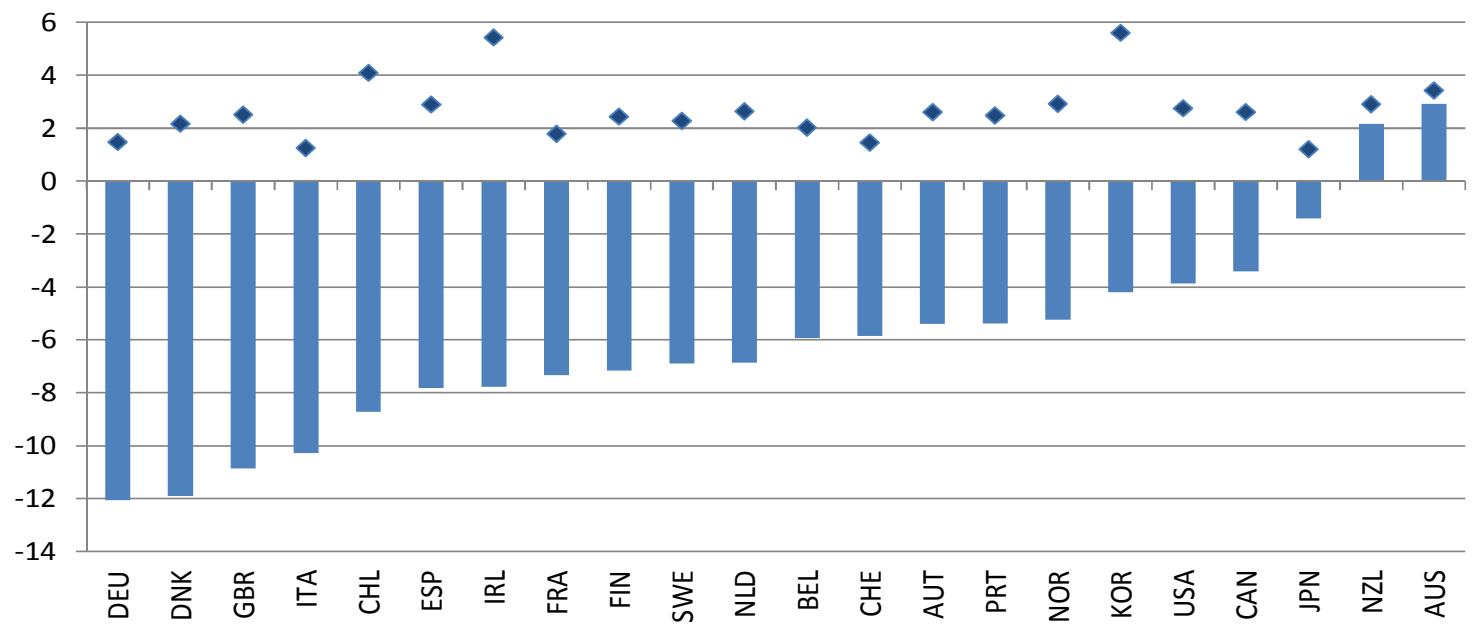

$\mathrm{NO}_{\mathrm{x}}$ emissions growth rate

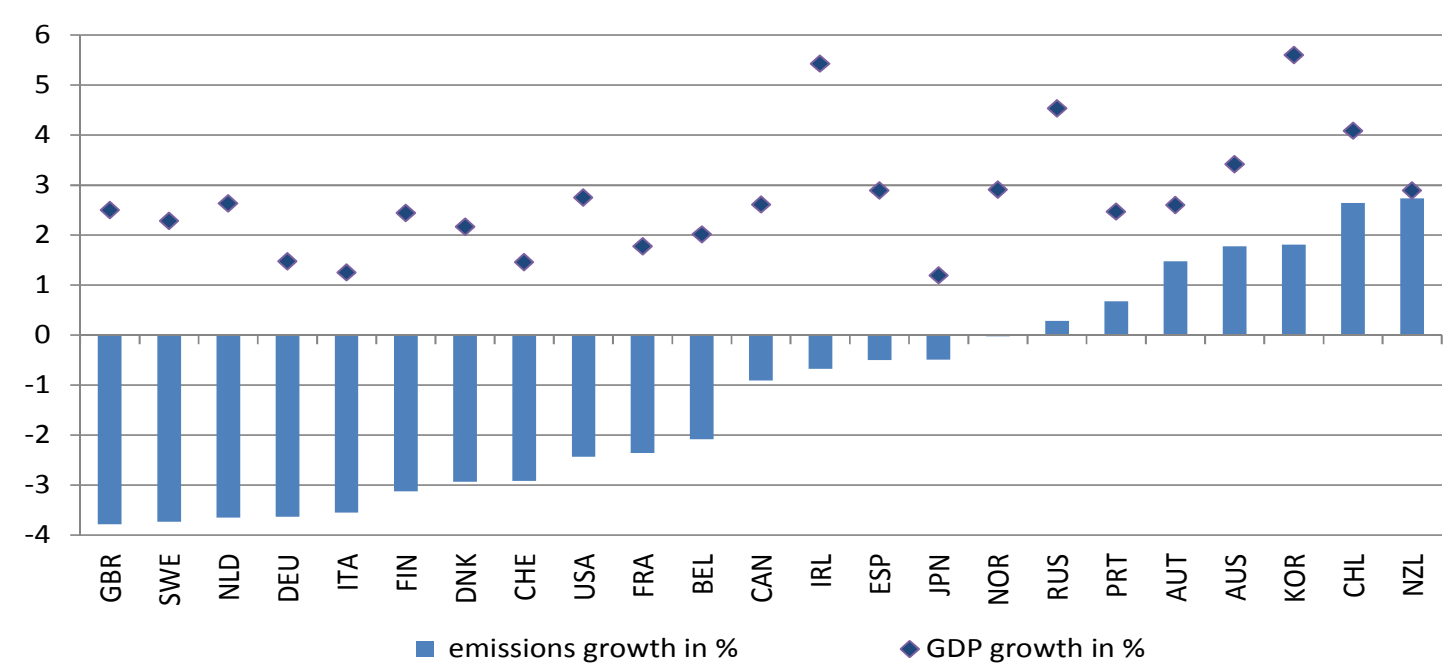


30. With emissions growth below GDP growth, the correction of the traditional MFP measure for the effect of bad outputs is positive. This is easy to see by taking a look at equations (5) and (6). The upward correction of the MFP growth measure resulting from the inclusion of different bad outputs is shown in Figure 2. It is the average effect over the sample period in percentage points, equivalent to the last term in equations (5) and (6). The effect of the inclusion of $\mathrm{CO}_{2}$ is largest in Russia, followed by Ireland, the United Kingdom and Sweden. The effect of $\mathrm{SO}_{\mathrm{X}}$ reduction is particularly large in the United Kingdom, Ireland, Germany, Denmark and Chile. Nearly all of these countries, along with Finland, the Netherlands and Italy, also achieved a particularly large reduction in $\mathrm{NO}_{\mathrm{X}}$ emissions. Over the sample period, the average total adjustment was largest in Ireland, the United Kingdom and Sweden. It was comparatively low in New Zealand, Australia and Japan. Data for Mexico and South Africa are not comparable, because they do not include $\mathrm{SO}_{\mathrm{X}}$ or $\mathrm{NO}_{\mathrm{X}}$ emissions.

Figure 2. Contributions to productivity adjustment of individual pollutants ${ }^{1)}$

Average annual adjustment in percentage points, 1991 - 2008

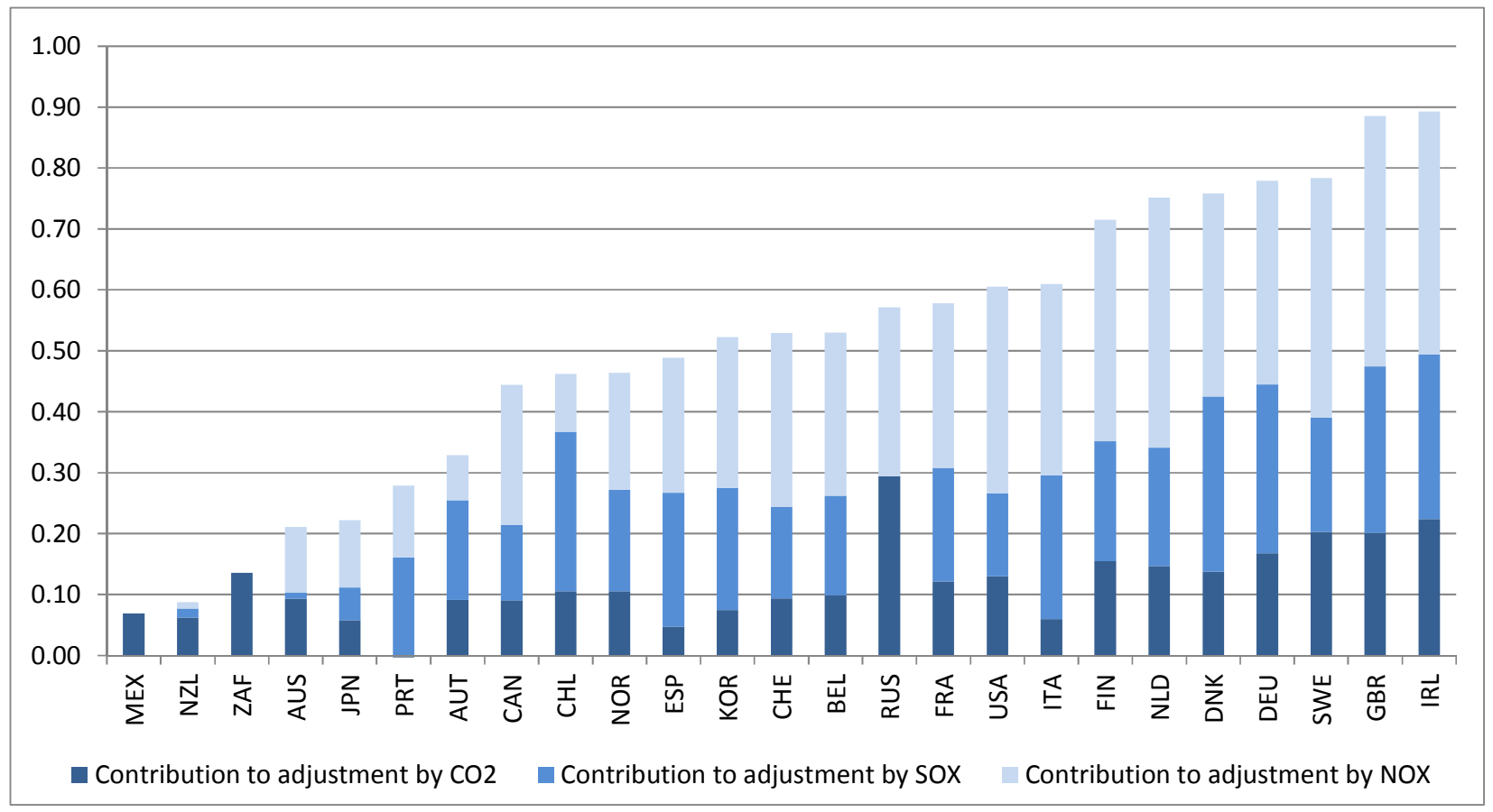

1. Bad output elasticities used for this calculation correspond to the central estimates of the regression with fixed effects and time dummies, as presented in table 2.

31. The interpretation of this upward correction is that the traditional MFP measure fails to take into account environmental technological progress. If some inputs are devoted to reducing bad outputs rather than to increasing the production of goods and services, as producers invest in cleaner technologies, a productivity growth measure that considers only the growth in goods and services outputs will underestimate productivity growth. It should be noted, though, that the adjustment of productivity growth at the aggregate economy level does not only capture the effect of cleaner technologies, but also structural change towards sectors that are subject to fewer emissions, such as services.

32. At the same time, the correction of the traditional MFP measure for the bad outputs considered in this study is rather small. Using the central estimates for bad output elasticities, the average correction of the traditional MFP measure for all three bad outputs combined exceeds half a percentage point in only a few cases. The largest average combined correction is a bit above 0.7 percentage points for the United 
Kingdom and Ireland. The reason that relatively large differences in growth rates of GDP and bad outputs translate into rather small correction of MFP growth is that the elasticity of bad outputs is low.

33. The correction of the MFP growth is subject to considerable uncertainty. The $95 \%$ confidence interval for the countries with the largest average correction in the sample period ranges from a low of 0.2 percentage points to a high of well above 1 percentage point (Figure 3). In most countries, however, even the upper limit of the confidence interval remains well below 1 percentage point.

Figure 3. MFP growth adjustment for $\mathrm{CO}_{2}, \mathrm{SO}_{x}$ and $\mathrm{NO} x$ with $95 \%$-confidence interval ${ }^{1)}$

In percentage points

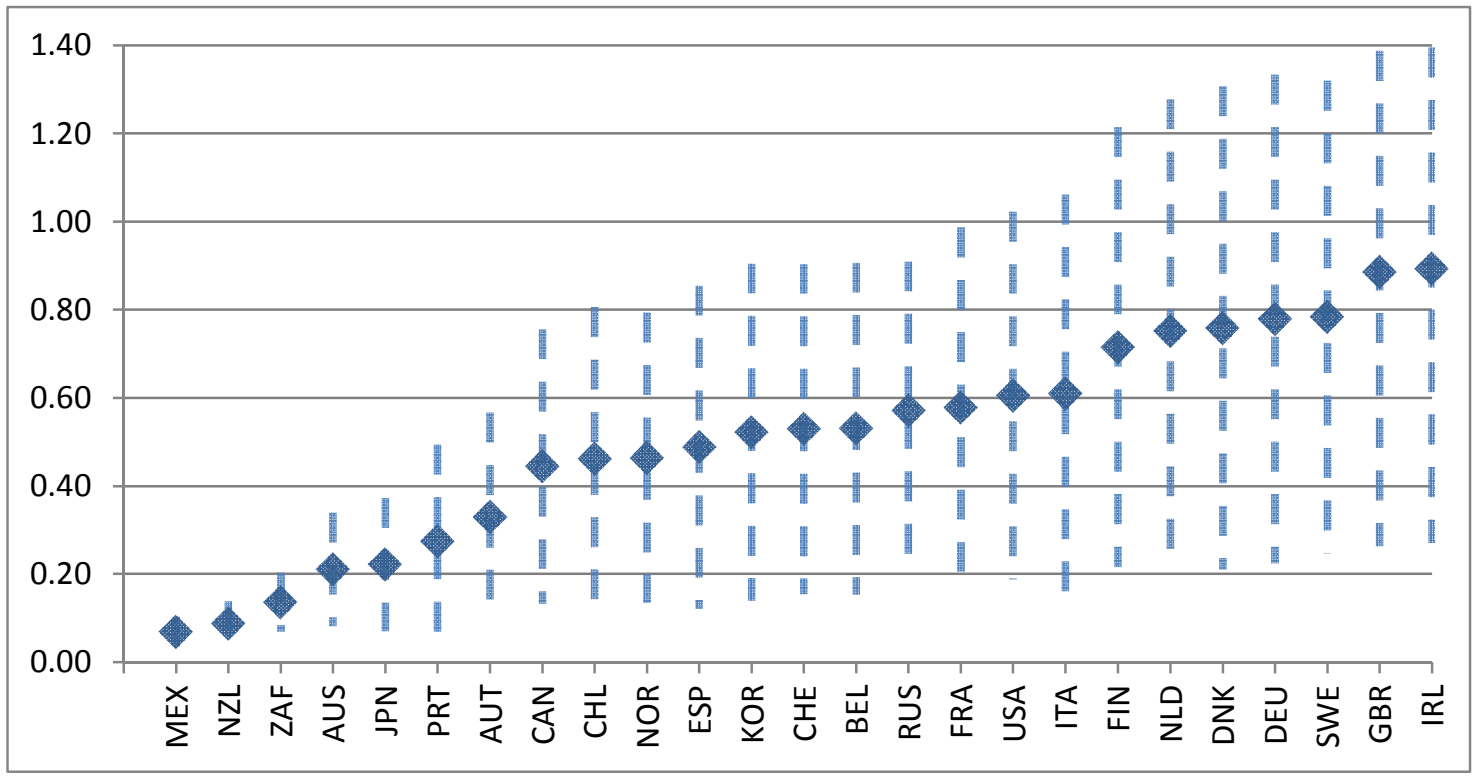

1. Bad output elasticities used for this calculation correspond to the central estimates of the regression with fixed effects and time dummies, as presented in table 2 , and its $95 \%$ confidence interval.

34. The average adjustment for bad outputs can mask important variations over time. Figure 4 shows the development of traditional MFP growth, including natural capital as an input factor, and the extended MFP measure that is adjusted for bad outputs over time (GMFP). The adjustment is always positive in the United Kingdom and the United States, although with important variations over the years. In the United States, it is hardly detectable at the beginning of the sample period and becomes larger over time. In South Africa, the low average adjustment is a result of a consistently low, but mostly positive, adjustment over the whole sample period, while in New Zealand it is the result of swings from positive to negative adjustments. In all cases it remains true that the adjustment is rather low, although the $95-\%$ confidence interval does reach up to 2 percentage points at a few data points for the United Kingdom and the United States. 
Figure 4. MFP growth adjustments over time ${ }^{1}$

In percentage points

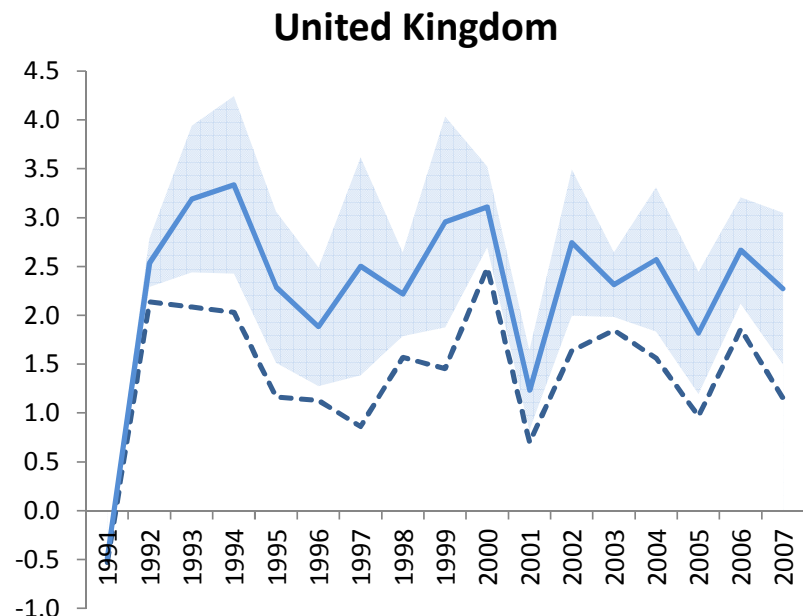

New Zealand

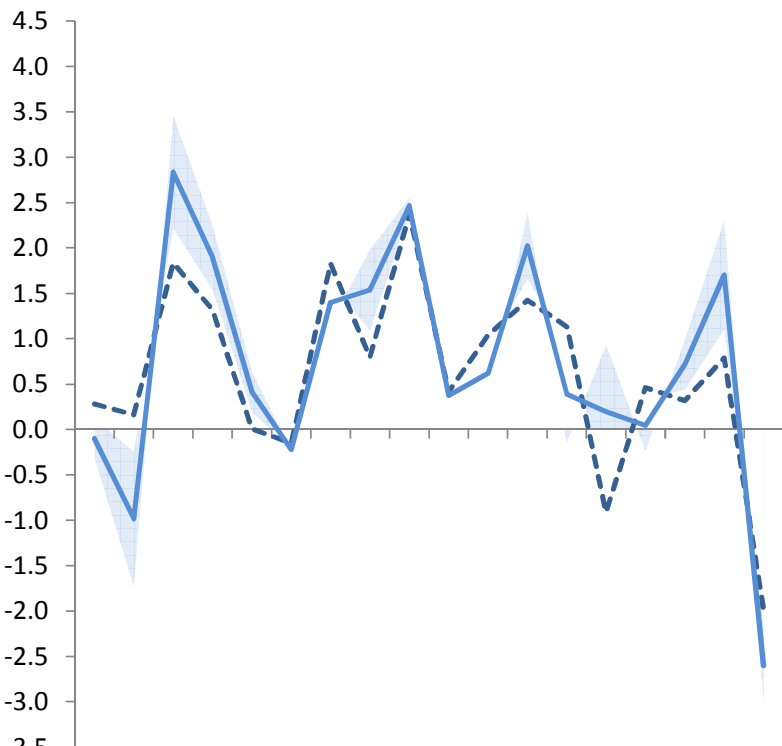

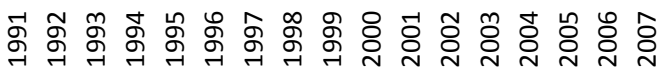

United States

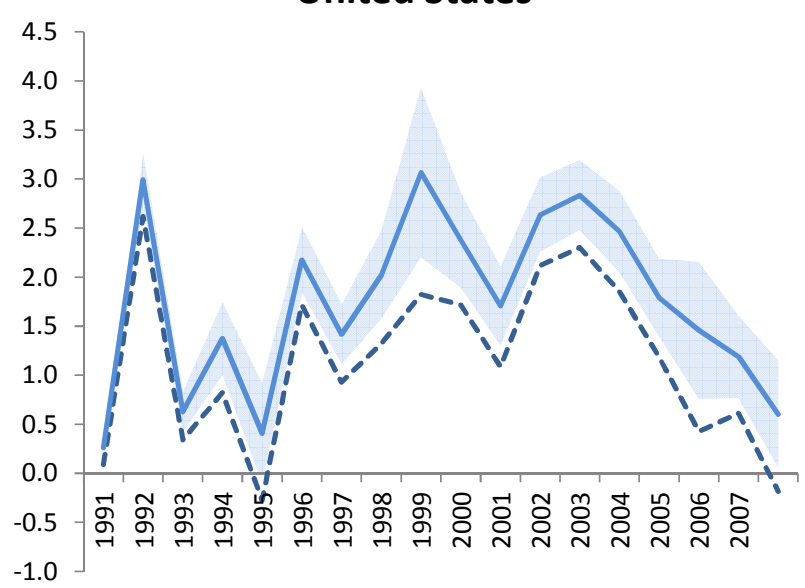

South Africa

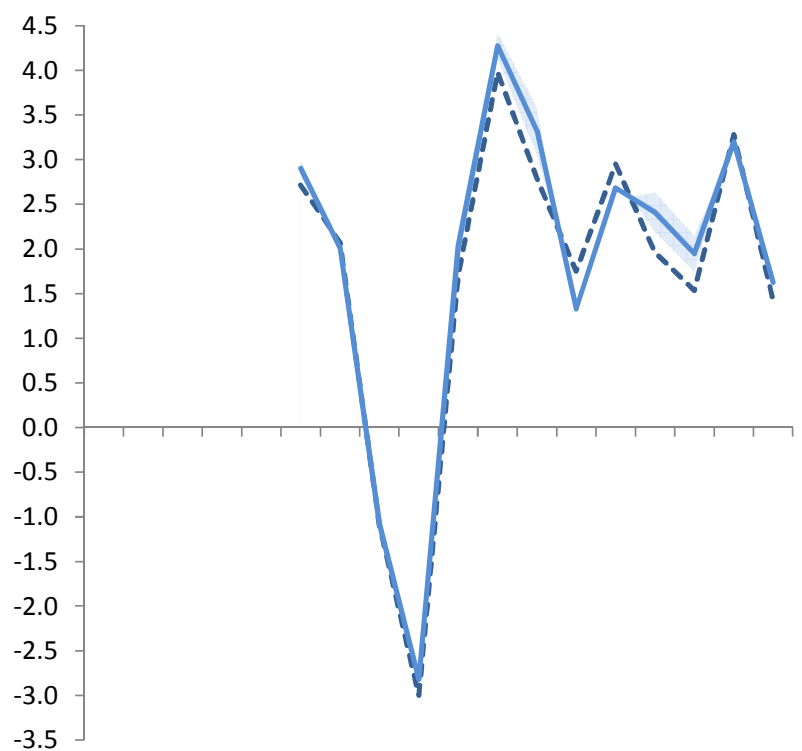

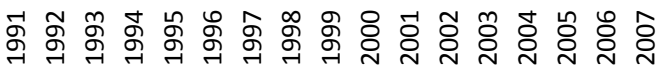

1. Bad output elasticities used for this calculation correspond to the central estimates of the regression with fixed effects and time dummies, as presented in table 2 , and its $95 \%$ confidence interval.

35. The relatively low adjustment of the traditional MFP measure contains at least two happy messages. One is that traditional productivity growth estimates and assessments of potential GDP growth are probably not too far off and overall the bias resulting from ignoring environmental bads is probably limited. The second, perhaps more important one, is that it should not be too difficult to reduce bad outputs 
further. As discussed above, a low elasticity of bad outputs implies that the increase in input or productivity growth that is needed to reduce bad output growth below its current level without lowering GDP growth is not too large. However, it should be kept in mind that this analysis is based on historical values. The whole picture could change significantly in the future: Marginal abatement costs have been relatively low in the past as low hanging fruits were harvested first. If marginal abatement costs were to rise significantly in the future, the difference between the traditional and adjusted productivity measure might become more important. In that context, further research on the topic of adjusted productivity measures will be needed.

\section{Costs of further emission reductions in terms of GDP - A simulation exercise}

36. To illustrate the results' implications for bad output reductions in the future, let's consider a relatively ambitious target to reduce emissions further. Let's assume that all countries in the sample want to reduce emissions to $10 \%$ of their 1990 levels by 2050, which would probably be sufficient to limit temperature increases to 2 degrees Celsius according to scientific studies. For $\mathrm{CO}_{2}$ this would imply that starting from 2009 levels, which is the last year for which data is available for most countries in the sample, emissions would have to decrease by an average of $6 \%$ every year. Given that $\mathrm{CO}_{2}$ grew at a positive rate in many countries until 2009, the required reduction in $\mathrm{CO}_{2}$ emission growth compared to the average rate between 1990 and 2009 would be larger than that, between 6 and 8 percentage points for most countries. Panel 1 in Figure 5 compares the annual average GDP growth over 1991-2008 with hypothetical growth rate that would result from such a radical reduction in $\mathrm{CO}_{2}$ emissions, if the rate of growth of inputs and of green MFP stayed the same. These numbers can be inferred relatively easily from equation (2), using the estimates for elasticities presented in this paper (Annex 4). As can be seen in Figure 5, the resulting reduction in annual GDP growth would not be very large, although it is true that over the period of 40 years considered in this thought experiment this would accumulate to quite a substantial reduction in the income level.

37. However, reductions in GDP growth could be avoided if countries could manage to increase MFP growth at the same time. Panel 2 in Figure 5 shows the average in MFP growth - adjusted for $\mathrm{CO}_{2}$ emissions - over 1991-2009 along with the higher rate that countries would have to achieve to reduce their emissions to $10 \%$ of 1990 levels by 2050 without increasing input growth or suffering any losses in output growth. Considering how ambitious a reduction to $10 \%$ of 1990 levels would be, the required improvement in productivity growth does not seem overly large.

38. If countries joined their efforts to put in place efficient and effective policies, it should be possible to achieve this increase in productivity growth. Such policies would include a withdrawal of harmful subsidies, a price on $\mathrm{CO}_{2}$ emissions to internalise their impact on climate change with its potentially devastating effects, along with investment in R\&D and support for technology deployment to spur the development of new and cleaner technologies. 
Figure 5. Simulated adjustment in GDP or productivity growth to bring $\mathrm{CO}_{2}$ emissions to $10 \%$ of 1990 levels by 2050

I. Annual average GDP growth, 1991-200,8 compared to the hypothetical growth rate until 2050 that would result from a decrease of $\mathrm{CO}_{2}$ emissions to $10 \%$ of 1990 levels, ceteris paribus

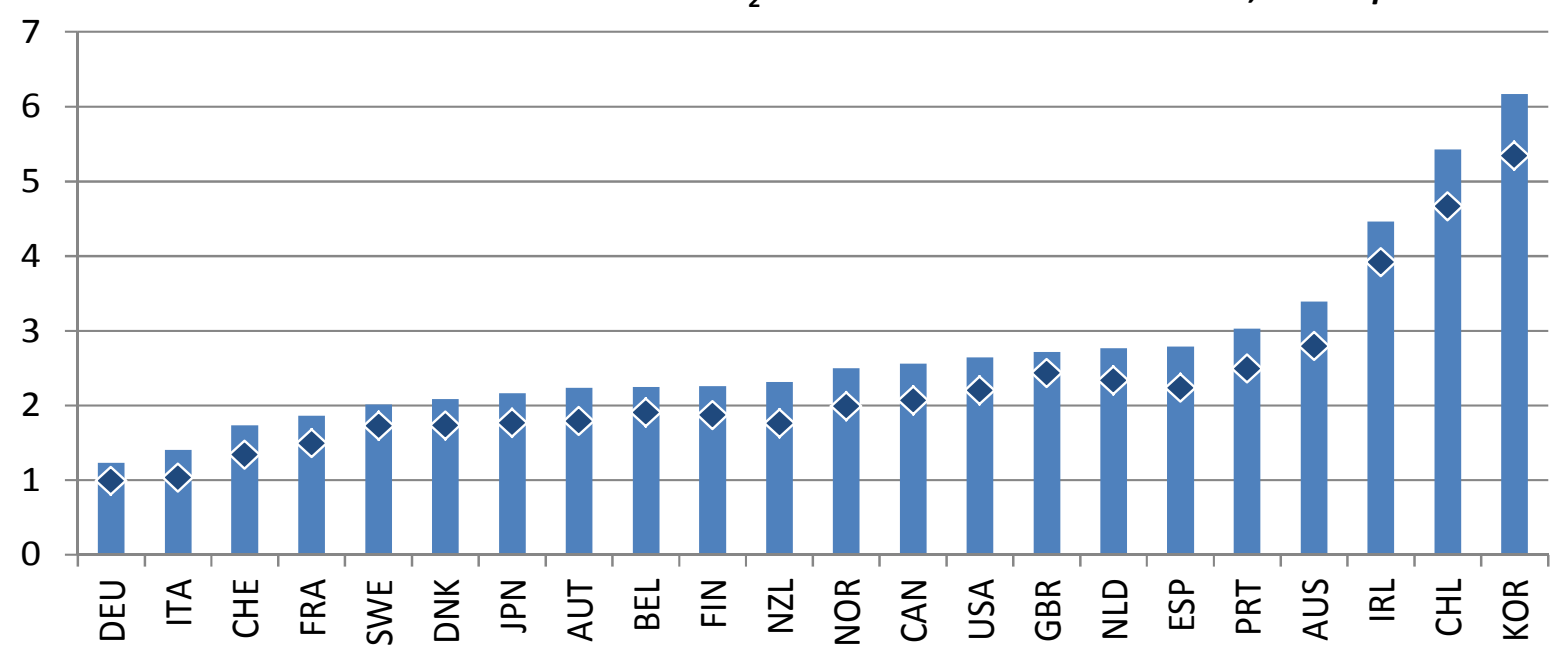

GDP growth, 1991 - 2008 average $\bullet$ hypothetical GDP growth, 2009-50 average

II.Annual average productivity growth, 1991-2008, compared to hypothetical growth rate until 2050 that would result from a decrease of $\mathrm{CO}_{2}$ emissions to $10 \%$ of 1990 levels, ceteris paribus

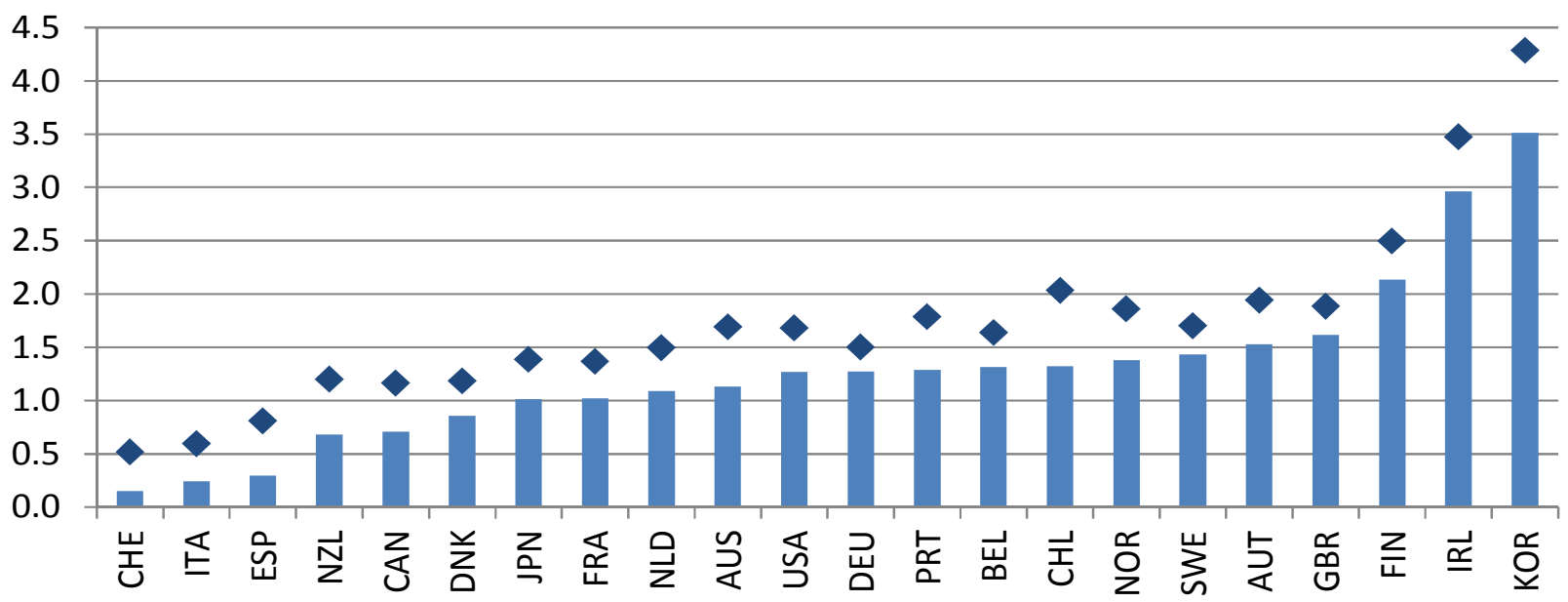

GMFP growth rate (adj. only for CO2 emissions), 1991 - 2008 average

$\downarrow$ GMFP growth, 2009-2050 average, with CO2 emission reduction

39. Reducing $\mathrm{SO}_{\mathrm{X}}$ and $\mathrm{NO}_{\mathrm{X}}$ emissions to $10 \%$ of 1990 levels would be easier, given emission reductions already achieved in the past. In fact, some countries could even reduce the rate of reduction in these emissions and still reduce them to $10 \%$ of 1990 levels by 2050. Figure 6 shows the example for $\mathrm{SO}_{\mathrm{X}}$ emissions. The required adjustment of GDP and MFP growth to achieve the desired reduction in $\mathrm{SO}_{\mathrm{X}}$ emissions is very low, owing to the low elasticity of $\mathrm{SO}_{\mathrm{X}}$. Nevertheless, it can be seen from Figure 7 that in a number of countries GDP growth could even increase or GMFP growth decline. The interpretation is that if the average growth rates of productivity outputs and inputs stayed the same as during 1990-2009, $\mathrm{SO}_{\mathrm{X}}$ 
would decline to even less than $10 \%$ of 1990 levels and no additional adjustment is needed. The picture for $\mathrm{NO}_{\mathrm{X}}$ emissions (not shown) looks similar.

Figure 6. Simulated adjustment in GDP or productivity growth to bring SOx emissions to $10 \%$ of 1990 levels

I. Change in GDP growth to bring $\mathrm{SO}_{\mathrm{x}}$ emissions to $10 \%$ of 1990 levels

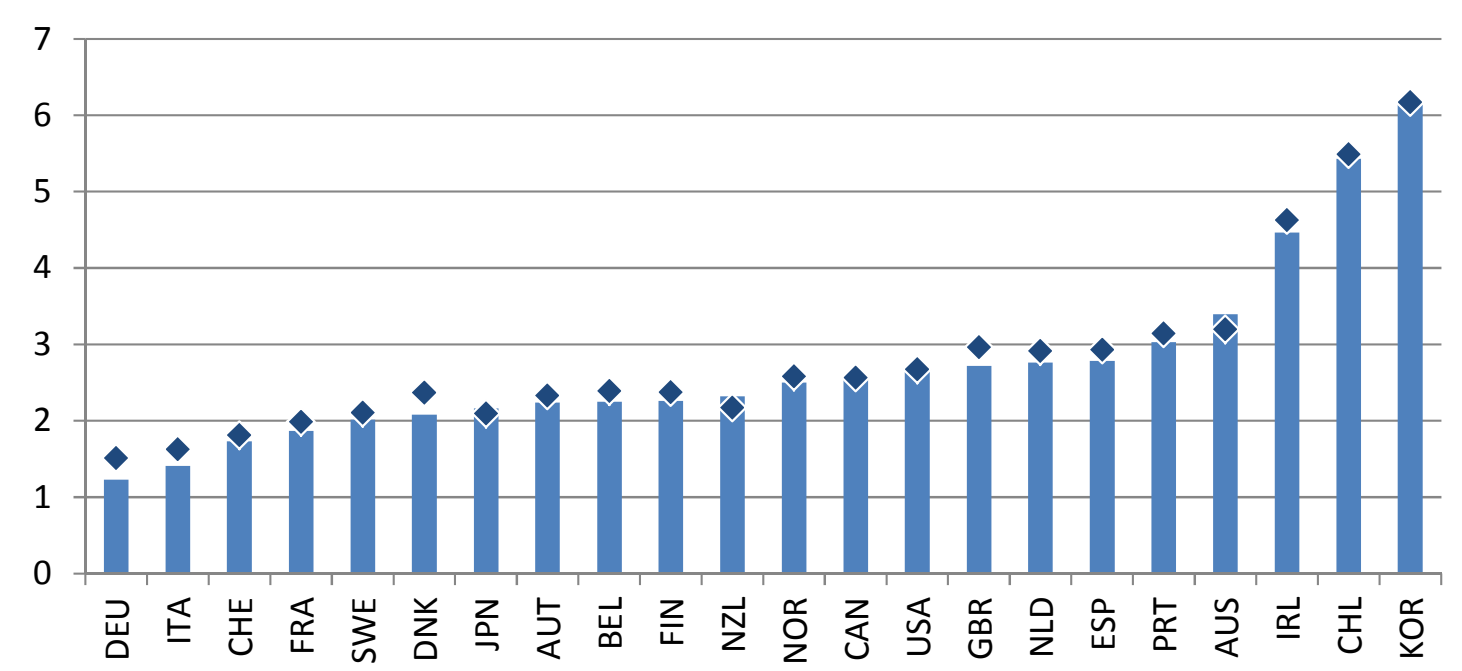

GDP growth, 1991 - 2008 average $\quad$ hypothetical GDP growth, 2009-50 average

II. Change in GMFP growth to bring $\mathrm{SO}_{\mathrm{X}}$ emissions to $10 \%$ of 1990 levels

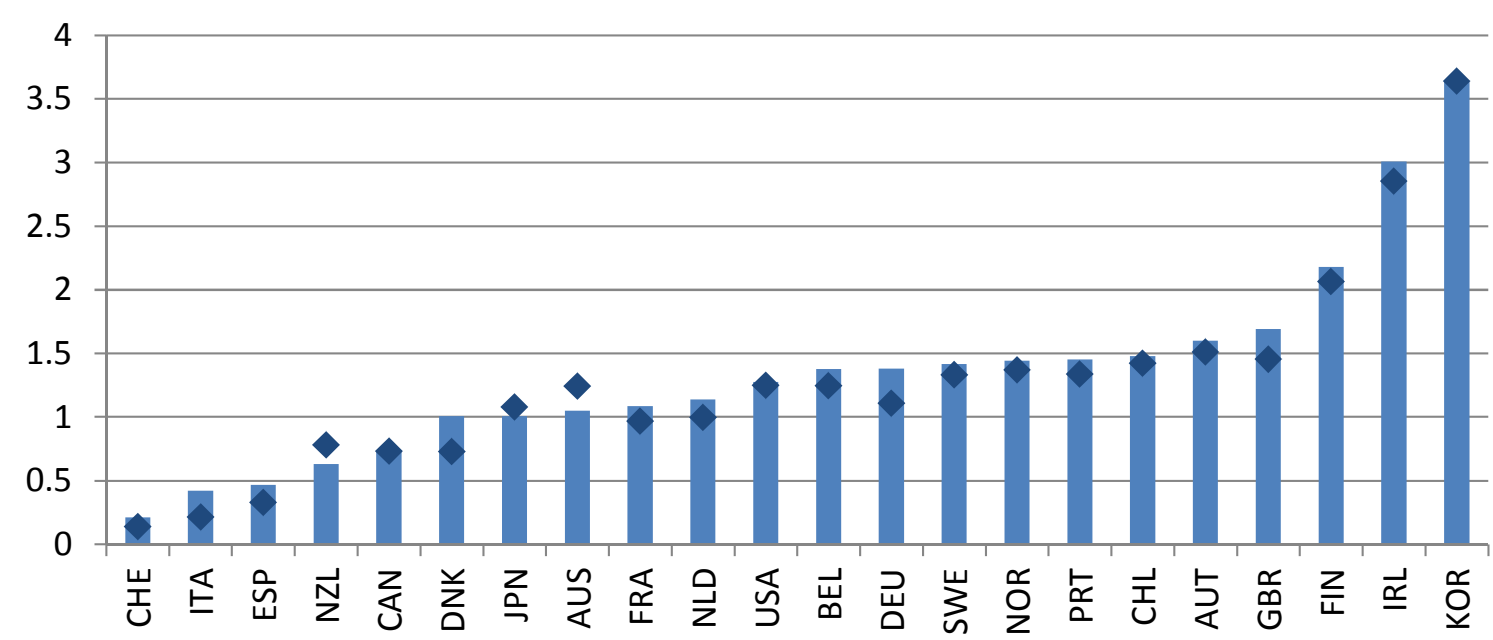

GMFP growth rate (adj. only for SOX emissions), 1991 - 2008 average

$\downarrow$ GMFP growth, 2009-2050 average, with SOX emission reduction 


\section{Shadow prices implied by the estimated elasticities of bad outputs}

40. It is interesting to take a look at the shadow prices that are implied by the elasticity estimates for bad outputs presented above. The shadow price of bad outputs can be derived from the estimated parameter $\alpha_{2}$ in equation (8) as (Annex 3):

$P_{\text {Rit }}=-\alpha_{2} * \frac{P_{Y i t} Y_{i t}}{R_{i t}}$

41. These shadow prices are interesting by themselves, as they reflect the average stringency of regulations constraining emissions in the economy. As shown in Annex 1-3, they correspond to the marginal abatement cost for emissions, which will depend on government policies restricting emissions.

42. The implied central estimates for shadow prices for $\mathrm{CO}_{2}$ (Figure 7) are plausible in the sense that countries which effectively subsidise fossil-fuel based electricity, such as South Africa and Russia (IEA, 2011), have relatively low $\mathrm{CO}_{2}$ shadow prices. In North-American countries, Australia and New Zealand, where fuel taxes are relatively low and regulations which constrain $\mathrm{CO}_{2}$ emissions may generally be thought to be more lenient than in Europe, estimated shadow prices are also lower than in European countries. Sweden and Norway, on the other hand, two countries with explicit $\mathrm{CO}_{2}$ taxes, have relatively high shadow prices. The shadow prices are negative, because avoiding $\mathrm{CO}_{2}$ emissions results in reduced revenues from producing good output. In other words, the shadow price of each bad output is interpreted as its (negative) marginal abatement cost.

43. The order of magnitude of estimated shadow prices also seems plausible. It is well above $\mathrm{CO}_{2}$ prices currently observed in the European and other trading systems, but well within the range of $\mathrm{CO}_{2}$ prices implicit in energy taxes (OECD, 2013a) and model-based estimates of $\mathrm{CO}_{2}$ prices implicit in various policies in OECD countries (OECD, 2013b). The higher range of estimates presented here than prices observed in trading schemes should not come as a surprise, as countries employ many different, sometimes overlapping and conflicting policies, which could be expected to raise the costs above the simple trading scheme price. The $\mathrm{CO}_{2}$ prices of this paper lie also in the range of estimates of social costs of carbon (Tol, 2005 and 2008). The latter are often calculated on the basis of integrated assessment models but are subject to high uncertainty and vary depending on the underlying assumptions made (Pindyck, 2013). A considerable uncertainty regarding the exact size of shadow prices is also found with the estimates presented here, as evidenced by the size of the confidence interval surrounding central estimates. 
Figure 7. $\mathrm{CO}_{2}$ shadow prices ${ }^{1)}$

2008 value central estimate with $95 \%$ confidence interval

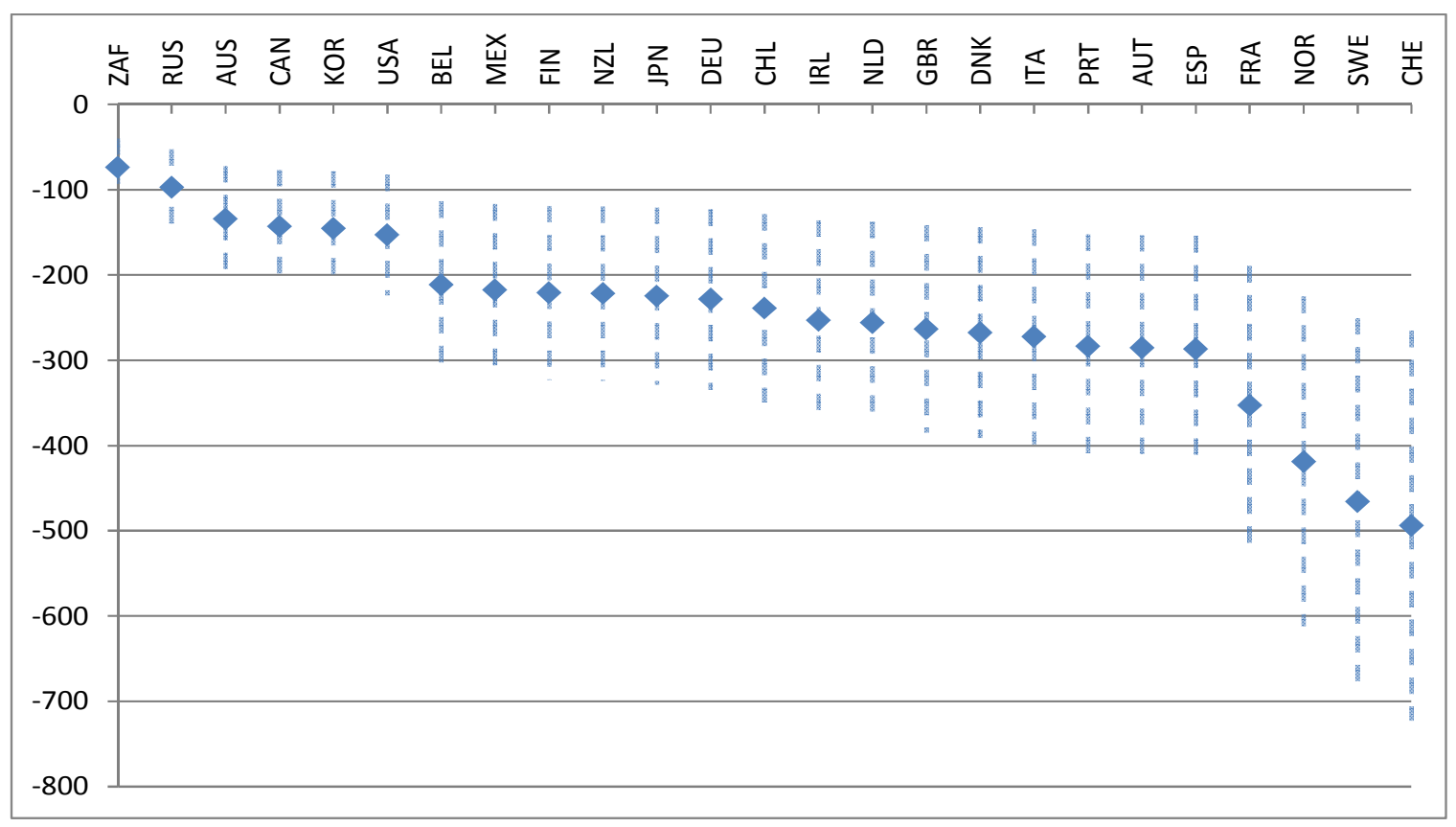

1. Based on coefficient estimates from the regression with time dummies and fixed effects (table 2).

44. Shadow prices increase over the whole sample period (Figure 8). This is because nominal GDP has risen faster than $\mathrm{CO}_{2}$ emissions over the sample period. With constant elasticities ${ }^{3}$, this implies increasing $\mathrm{CO}_{2}$ shadow prices over time (equation (10)). This rise in shadow prices can be interpreted as an increase in the strictness, with which $\mathrm{CO}_{2}$ emissions have been regulated over time, which is certainly what happened in most, if not all countries in the sample.

3. Time-invariant coefficients are supported by the data, in that interactions with time dummies for various sub-periods were found not to be significant. 
Figure 8. Shadow prices in South Africa and Switzerland ${ }^{1)}$

In USD per ton with $95 \%$ confidence interval

\section{South Africa}

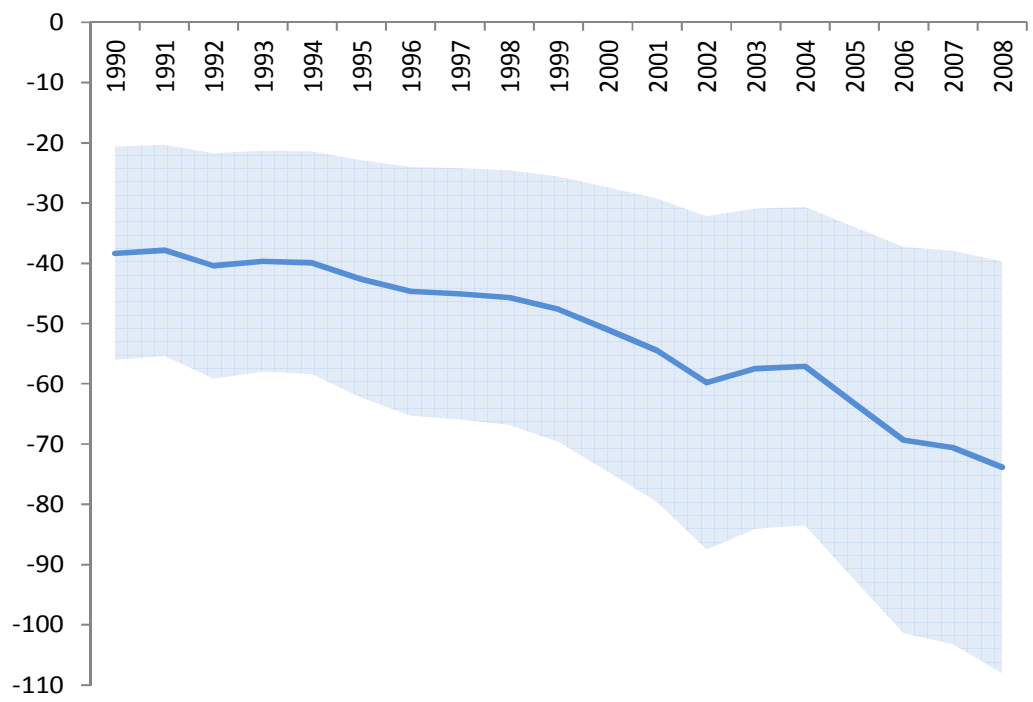

Switzerland

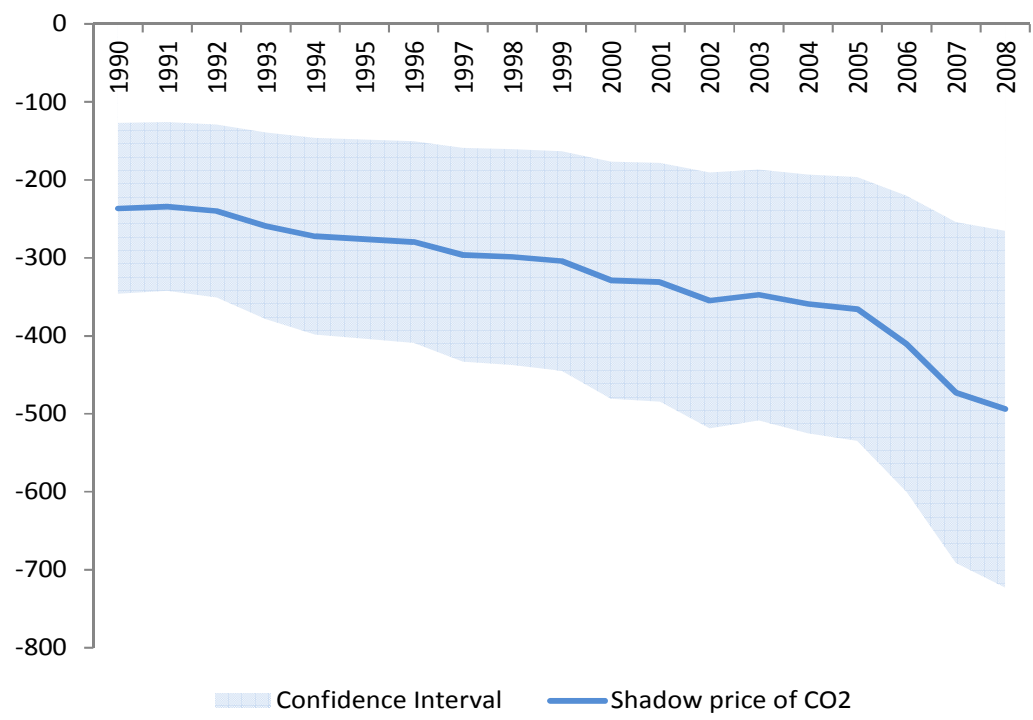

1. Based on coefficient estimates from the regression with time dummies and fixed effects (table 2).

45. Shadow prices for $\mathrm{SO}_{\mathrm{X}}$ and $\mathrm{NO}_{\mathrm{X}}$ display a similar pattern. They tend to be lower in North America, Australia and New Zealand than in European countries. They also increase quite sharply over time, as emissions have actually fallen in many countries. 
Figure 9. $\mathrm{NO}_{\mathrm{x}}$ and $\mathrm{SO}_{\mathrm{x}}$ shadow prices ${ }^{1)}$

2008 values in 1000 USD per ton with 95\% confidence interval

$\mathrm{NO}_{\mathrm{x}}$ shadow prices

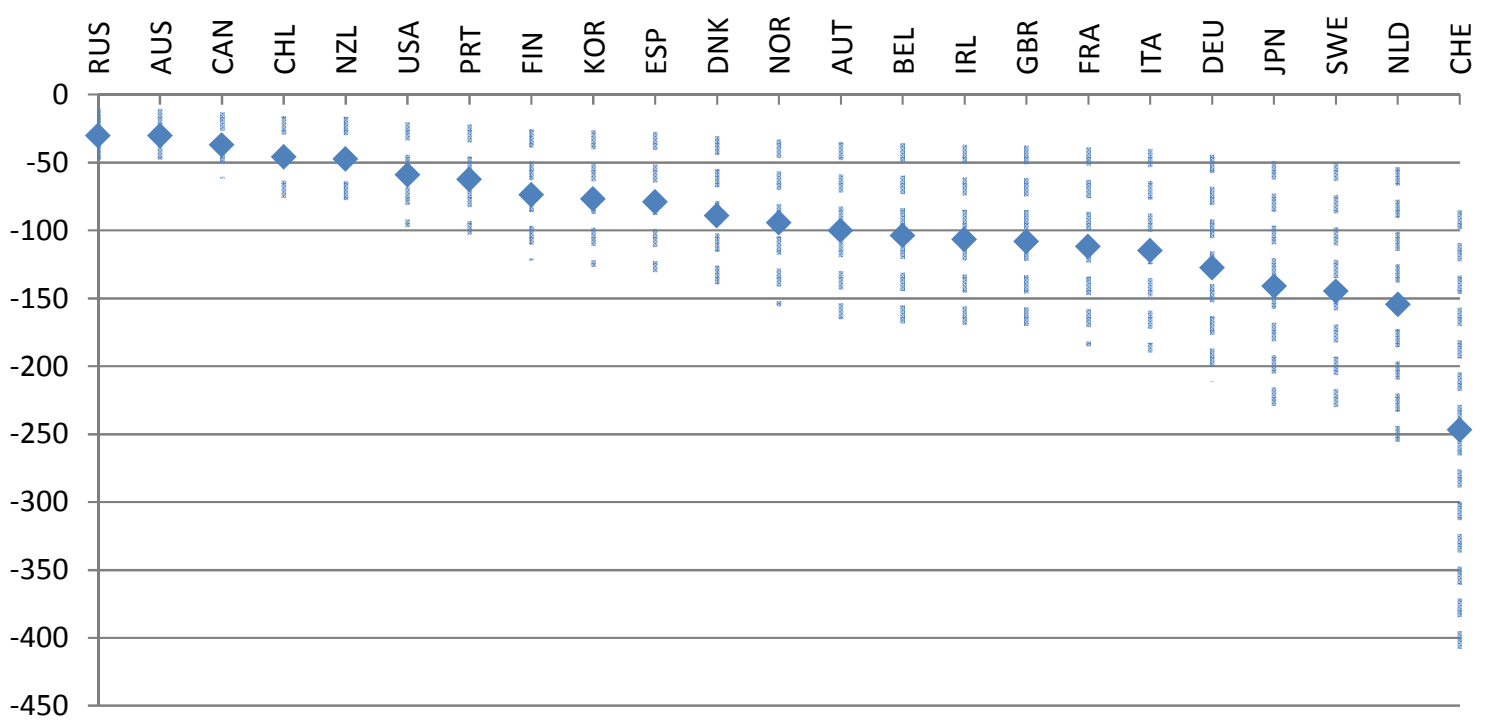

SO $_{\mathrm{X}}$ shadow prices

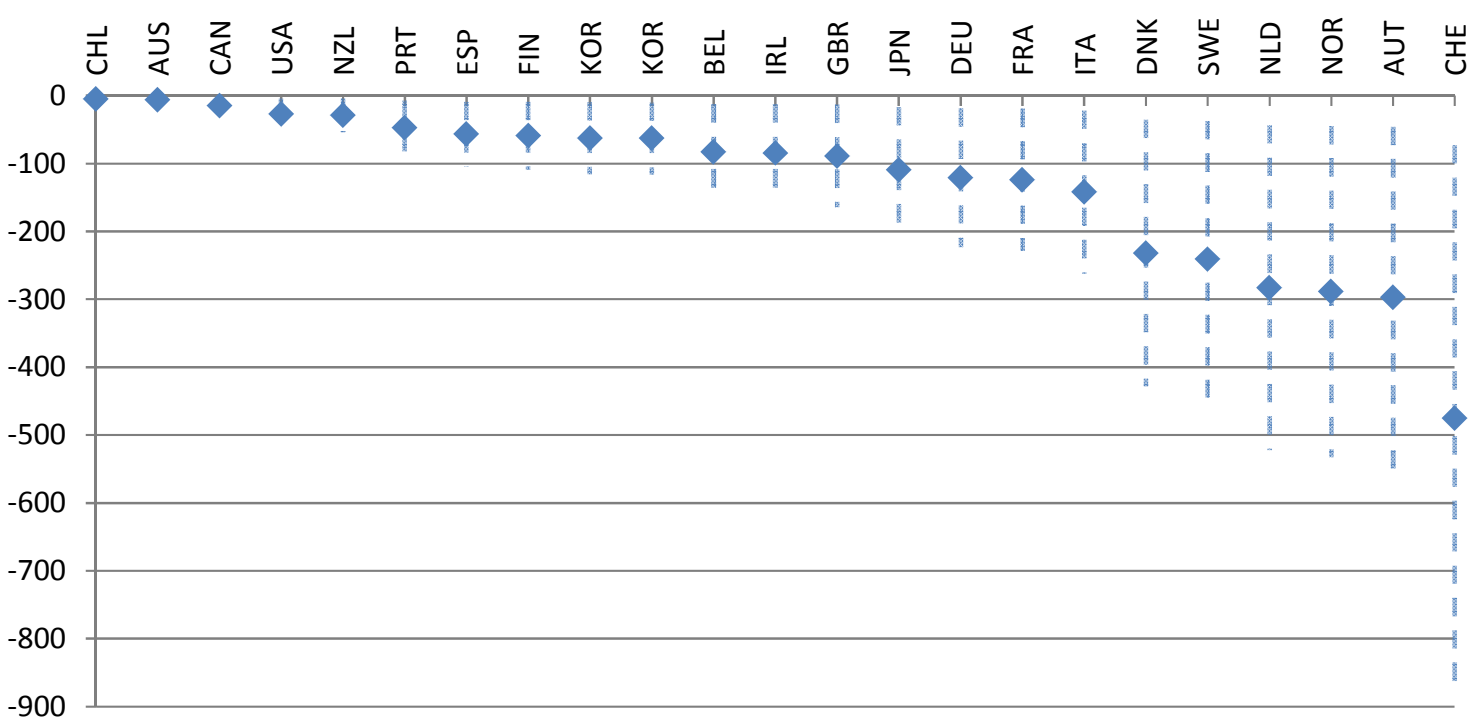

1. Based on coefficient estimates from the regression with time dummies and fixed effects (table 2).

46. It is difficult to assess what a plausible shadow price estimate for $\mathrm{NO}_{\mathrm{X}}$ and $\mathrm{SO}_{\mathrm{X}}$ might be. These emissions are mainly constrained by various regulations and economy-wide assessments of costs of complying with these regulations are not available. The estimates presented in Figure 9 do seem very high when compared to taxes on these emissions, such as the tax on $\mathrm{NO}_{\mathrm{x}}$ emissions in Sweden which is 7800 USD per ton, or the highest price in the $\mathrm{NO}_{\mathrm{X}}$ trading scheme in the US electricity sector, which was 8000 USD per ton in 2003. The $\mathrm{SO}_{\mathrm{X}}$ trading scheme in the US electricity sector saw its highest price in 2006, 
with a price of 885 USD per ton of $\mathrm{SO}_{\mathrm{x}}$. While these, partly sector specific, prices do seem very high, they do not necessarily imply that the economy-wide cost to producers for complying with various regulations might not be closer to the numbers presented in Figure 9, for at least two reasons. First, the majority of $\mathrm{SO}_{\mathrm{X}}$ and $\mathrm{NO}_{\mathrm{X}}$ policies are emission limit values or technology standards. The implicit costs of these standards are not directly observable to the public and hence it might be more feasible to implement command-and-control mechanisms that are much more stringent than emission taxes or emission trading scheme caps. Second, the rather long history of $\mathrm{SO}_{\mathrm{X}}$ and $\mathrm{NO}_{\mathrm{X}}$ policies, compared to $\mathrm{CO}_{2}$ policies, might imply higher abatement costs as the low marginal abatement cost solutions might be exhausted.

47. Rather than taking these numbers as precise estimate of marginal abatement costs for $\mathrm{SO}_{\mathrm{X}}$ and $\mathrm{NO}_{\mathrm{X}}$ at the aggregate economy level, they should be viewed as an upper bound. As such, they are a very conservative basis for estimates of the potential bias of traditional MFP measures that might stem from excluding these emissions from the measurement. It is evident from equation (5) and (6) that the adjustment of the traditional MFP measure for these emissions would be even smaller, if their elasticity and thus their shadow price- were smaller than what the estimates presented here suggest. Moreover, lower shadow prices for $\mathrm{SO}_{\mathrm{X}}$ and $\mathrm{NO}_{\mathrm{X}}$ would only reinforce the message that achieving further emission reductions should not be too difficult. With lower shadow prices, the elasticities of the corresponding emissions would be lower (see equation (10)), and thus the reduction in GDP growth required to reduce these emissions further - if any - it would be even below what is shown in Figure 6.

\section{Conclusions}

48. All countries investigated in this paper have achieved environmental technological progress in the sense that the growth rate of emissions was lower than GDP growth over the period considered in this paper. This implies that traditional MFP growth measures underestimate productivity growth, because they do not account for the fact that countries have employed some inputs to reduce emission growth rather than increase GDP growth. Production in these countries has become relatively cleaner.

49. The productivity growth measure presented in this paper, that takes emissions into account, is not much larger than the traditional MFP growth, however. This owes largely to the small elasticity of bad outputs. While the exact size of these elasticities is subject to considerable uncertainties, it is quite certain that they must be much lower than those of labour and produced capital. Anything else would imply shadow prices of a dimension that would be impossible to imagine. This paper presents econometric estimates for shadow prices of $\mathrm{CO}_{2}, \mathrm{NO}_{\mathrm{X}}$ and $\mathrm{SO}_{\mathrm{X}}$ emissions, which imply plausible shadow prices for $\mathrm{CO}_{2}$. The implied shadow prices for $\mathrm{NO}_{\mathrm{X}}$ and $\mathrm{SO}_{\mathrm{X}}$, and thus also the elasticities from which they are derived, may appear to be at the high end, although it must be kept in mind that there is no obvious benchmark for this. It is simply very difficult to assess the costs of abating emissions for firms. In spite of elasticity estimates for bad outputs which are probably rather at the high end, the adjustment of traditional MFP growth for emissions remains low, overall. This suggests that ignoring the role of the bad outputs considered in this paper does not lead to a large bias of productivity growth estimates. This is re-assuring, as it means that analysis of technological progress, potential output and other issues based on traditional productivity growth measures is unlikely to lead to wrong conclusions, because the role of $\mathrm{CO}_{2}, \mathrm{NO}_{\mathrm{X}}$ and $\mathrm{SO}_{\mathrm{X}}$ emissions was ignored. Nonetheless, with rising marginal abatement costs, the impact of bad outputs on productivity measures might increase in the future, demanding further research in the field of adjusted productivity measures.

50. Results presented in this paper also imply that considerable additional emission reductions can be achieved at reasonable costs. The low elasticity of bad outputs presented in this paper imply that the reduction in GDP growth that would have to be accepted to achieve very considerable emissions reduction over the coming decades is limited, even in the absence of further environmental technological growth. Conversely, the additional productivity growth that would be required to achieve the same emissions 
reductions without losses in output growth is not overly large. With efficient and effective policies that price the externalities associated with bad outputs, while promoting R\&D and new technology deployment through direct and indirect government support along with effective education policies, it should be possible to achieve the necessary technological progress that would allow countries to lower bad outputs without suffering income losses.

51. One caveat to these conclusions is, however, that the list of bad outputs considered in this paper is limited. $\mathrm{NO}_{\mathrm{X}}$ and $\mathrm{SO}_{\mathrm{X}}$ are very important air pollutants, but there are many others, such as non-methane volatile organic compounds (NMVOCs), ammonia (NH3), fine particulate matter (PM10 and PM2.5), toxic heavy metals (such as arsenic, cadmium, chromium, lead, mercury and nickel) and organic micropollutants: benzene, dioxins and furans, and polycyclic aromatic hydrocarbons (PAHs); secondary pollutants that are built through chemical reactions of other pollutants; the pollution of water and soil through nutrients, such as nitrogen and phosphates; and the destruction of ecosystems through paving of soil, which can lead to both floods and water scarcities, and through other constructions, such as dams and hydropower plants. Considering more of these bad outputs would almost certainly result in a bigger adjustment of the traditional MFP growth measure, although it will probably remain the case that the adjustment for each additional bad output will remain small.

52. Additional insights may be gained by looking at industry-level data. While the impact of bad outputs is probably small in services sectors, which contribute the largest share to GDP at least in OECD countries, the impact is likely to be much larger in the electricity sector, in transport, in some industries and in agriculture, depending on the bad output considered. Also, looking at the mining sector in isolation is likely to yield interesting results, both regarding bad outputs and the role of natural capital for growth.

53. This paper presents a framework that is appropriate to study the impact of environmental regulation on productivity. To understand the impact of environmental policies the output measure considered should include not only GDP, but also the bad outputs that environmental policies aim to reduce, as explained in the introduction. To judge the success of environmental policies, GDP is too narrow an output measure and asking what happened to traditional MFP growth is in a way asking the wrong question. In that sense, the framework presented here is well suited to study the impact of environmental policies on productivity. It will be interesting to link the results of this paper to measures that capture the general stance of environmental policy stringency, where work is currently being developed at the OECD. 


\section{APPENDIX 1}

1. Consider a technology $T$ that describes how good outputs, $Y$, and bad outputs, $R,(Y, R) \in R_{+}^{N}$, can be produced from inputs $\mathrm{X} \in \mathrm{R}_{+}^{\mathrm{M}}$

$\mathrm{T}(\mathrm{t})=\{(\mathrm{Y}, \mathrm{R}, \mathrm{X}) \mid \mathrm{X}$ can produce $(\mathrm{Y}, \mathrm{R})$ at time $\mathrm{t}\}$

This technology satisfies a set of axioms detailed in Färe and Primont (1995). Another way to describe this technology is the output distance function defined by Shephard (1970)

$H(Y, R, X)=\inf \left\{\varphi>0:\left(X, \frac{R}{\varphi}, \frac{Y}{\varphi}\right) \in T(t)\right\}$

which is the smallest scalar between zero and one by which outputs can be divided, in other words, the amount by which outputs can be increased, while keeping inputs constant. Note that $\varphi$ cannot be bigger than 1, because in that case there would always be a smaller scalar, 1, by which outputs can be divided so that $\left(\mathrm{X}, \frac{\mathrm{R}}{\varphi}, \frac{\mathrm{Y}}{\varphi}\right) \in \mathrm{T}(\mathrm{t})$ if $(\mathrm{Y}, \mathrm{R}, \mathrm{X}) \in \mathrm{T}(\mathrm{t})$. In fact, for $\varphi=1$ production is efficient in that outputs cannot increase without increasing inputs. In that sense

$H(Y, R, X, t)=1$

describes the production possibility frontier, that is the efficient set of outputs $(Y, R)$ where $t$ is an index of time. $\mathrm{H}$ is increasing in inputs and bad outputs and decreasing in good outputs: $H_{Y}<0 ; H_{R}, H_{X}>0$. This implies that more good output can be produced only by accepting more bad output: $\frac{d Y}{d R}=-\frac{H_{R}}{H_{Y}}>0$. The last equality follows from differentiating equation (A1.3) with respect to $\mathrm{R}$, keeping $\mathrm{X}$ and $\mathrm{t}$ (put not $\mathrm{Y}$ ) constant and re-arranging. In other words, avoiding bad output is costly, as it leads to foregone good output. $\mathrm{H}$ is homogenous of degree one in inputs and homogenous of degree -1 in outputs (see Färe and Primont, 2005). As a result it is homogenous of degree zero in inputs and outputs.

2. Totally differentiating equation (A1.3) with respect to time and re-arranging yields

$$
\begin{aligned}
& \frac{d \ln H}{d t}=-\sum_{i} \frac{H_{Y i} Y_{i}}{H} \frac{d \ln Y_{i}}{d t}-\sum_{i} \frac{H_{R i} R_{i}}{H} \frac{d \ln R_{i}}{d t}-\sum_{i} \frac{H_{X i} X_{i}}{H} \frac{d \ln X_{i}}{d t} \\
& \frac{d \ln H}{d t}=-\sum_{i} \varepsilon_{H Y_{i}} \frac{d \ln Y_{i}}{d t}-\sum_{i} \varepsilon_{H R_{i}} \frac{d \ln R_{i}}{d t}-\sum_{i} \varepsilon_{H X_{i}} \frac{d \ln X_{i}}{d t}
\end{aligned}
$$

where $\varepsilon_{\mathrm{HZ}}$ denotes the elasticity of the transformation function with respect to variable $\mathrm{Zi}$.

3. It can be shown that under profit maximisation the elasticity of the transformation function with respect to output $i$ equals its negative share in total revenues. For ease of presentation and in line with the data used in this paper, we present the proof with only one good output, Y, which can be thought of as GDP and one bad output, R, which like GDP can be thought of as a composite of different bad outputs, such that the rate of growth of the aggregate bad output is a weighted average of rates of growth of individual emissions: $\frac{d \ln R}{d t}=\sum_{i} \frac{P_{R i} R_{i}}{P_{R} R} \frac{d \ln R_{i}}{d t}$, with weights corresponding to each bad output's share in the total value bad outputs. If there was a tax on bad outputs, $\tau$, the profit maximization problem for producers operating with the technology described in equation (A1.3) would read: 
$\operatorname{Max} \mathcal{L}=P_{Y} Y-\tau \mathrm{R}-P_{X} X-\lambda(H(Y, R, X, t)-1)$

with first order conditions for $\mathrm{Y}: \frac{\partial \mathcal{L}}{\partial \mathrm{Y}}=\mathrm{P}_{\mathrm{Y}}-\lambda \mathrm{H}_{\mathrm{Y}}=0$ and $\mathrm{R}: \frac{\partial \mathcal{L}}{\partial \mathrm{R}}=-\tau-\lambda \mathrm{H}_{\mathrm{R}}=0$. From these conditions it follows that $-\tau=\mathrm{P}_{Y} \frac{\mathrm{H}_{R}}{\mathrm{H}_{\mathrm{Y}}}=-\mathrm{P}_{\mathrm{Y}} \frac{\mathrm{dY}}{\mathrm{dR}}=\mathrm{P}_{\mathrm{R}}<0$. In the optimum, producers would chose the bad output so that the tax they have to pay would equal the foregone revenue from reducing the bad output by one more unit. This corresponds to the marginal abatement cost of $\mathrm{R}$ or its shadow price from the producer perspective, which is thus negative.

4. If instead pollution was subject to a regulation, say a cap in absolute emissions $\mathrm{R} \leq \overline{\mathrm{R}}$ the optimisation problem would become:

$\operatorname{Max} \mathcal{L}=P_{Y} Y-P_{X} X-\lambda(H(Y, R, X, t)-1)-\mu(R-\bar{R})$

$\frac{\partial \mathcal{L}}{\partial Y}=P_{Y}-\lambda H_{Y}=0$ so

$\frac{\partial \mathcal{L}}{\partial R}=-\lambda H_{R}-\mu=0 ; \mu(R-\bar{R})=0 ;(R-\bar{R}) \leq 0 ; \mu \geq 0 ;($ Kuhn-Tucker conditions)

As long as the constraint is binding, $\mu$ will be non-negative. Combining the first order conditions it turns out that $-\mu=\mathrm{P}_{\mathrm{Y}} \frac{\mathrm{H}_{\mathrm{R}}}{\mathrm{H}_{\mathrm{Y}}}=-\mathrm{P}_{\mathrm{Y}} \frac{\mathrm{dY}}{\mathrm{dR}}=\mathrm{P}_{\mathrm{R}}$ corresponds to $-\tau$ in the tax case, so that $-\mu$ will equal the marginal abatement cost or the shadow price of $\mathrm{R}$ in the optimum, which is negative.

5. In both cases, the tax and the regulation case, it also follows that the elasticities of $\mathrm{H}$ with respect to $\mathrm{Y}$ and $\mathrm{R}$ correspond to the negative value shares of $\mathrm{Y}$ and $\mathrm{R}$ in the total value of outputs, $\rho=\sum P_{Y i} Y_{i}$ $+\sum P_{R i} R_{i}$, where good outputs are valued with their output prices and bad outputs are valued with their marginal abatement costs. To demonstrate this, insert the first order conditions into the equation that defines the total value of outputs:

$\rho=\sum P_{Y i} Y_{i}+\sum P_{R i} R_{i}=\lambda\left(H_{Y} Y+H_{R} R\right)$

As shown above, $H$ is homogeneous of degree -1 in $R$ and $Y$. It follows that $-H=H_{Y} Y+H_{R} R$. Inserting this expression into equation (A1.7) it follows that:

$\rho=-\lambda H$

With this identity and the first order conditions of the maximization problem above, it is possible to show that the elasticities of $\mathrm{H}$ with respect to its arguments $\mathrm{Y}$ and $\mathrm{R}$ equal the negative shares of $\mathrm{Y}$ and $\mathrm{R}$ in the total revenues:

$\varepsilon_{H Y_{i}}=\frac{H_{Y} Y}{H}=\frac{P_{Y} Y}{\lambda H}=-\frac{P_{Y} Y}{\rho}$

$\varepsilon_{H R_{i}}=\frac{H_{R} R}{H}=\frac{P_{R} R}{\lambda H}=-\frac{P_{R} R}{\rho}$

6. Similarly, it can be shown that the elasticities of the transformation function with respect to inputs equal their costs shares under cost minimisation. Take the cost minimization problem of producers

$\operatorname{Min} \mathcal{L}=P_{X} X-\lambda(H(Y, R, X, t)-1)$ 
With first order conditions: $\frac{\partial \mathcal{L}}{\partial X}=P_{X_{i}}-\lambda H_{X_{i}}=0$, for each $X_{i}$. Keeping in mind that $\mathrm{H}$ is linear homogenous in inputs $X$, it is possible to evaluate the Langrange multiplier in the optimum

$\gamma=\sum P_{X_{i}} X_{i}=\lambda \sum H_{X_{i}} X_{i}=\lambda H=\rightarrow \lambda=\frac{\gamma}{H}$

Given the valuation of $\lambda$ and the first order conditions, one obtains that the production elasticities of inputs equal their income share in total costs:

$\varepsilon_{H X_{i}}=\frac{H_{X_{i}} X_{i}}{X}=\frac{P_{X_{i}} X_{i}}{\lambda H}=\frac{P_{X_{i}} X_{i}}{\gamma}$

Given equations (A1.9), (A1.10) and (A1.13) it turns out that equation (A1.4) can be written as

$\frac{d \ln H}{d t}=\sum \frac{P_{Y i} Y_{i}}{\rho} \frac{d \ln Y_{i}}{d t}+\sum \frac{P_{R i} R_{i}}{\rho} \frac{d \ln R_{i}}{d t}-\sum \frac{P_{X i} X_{i}}{\gamma} \frac{d \ln X_{i}}{d t}$

where $\rho=\sum \mathrm{P}_{\mathrm{Yi}} \mathrm{Y}_{\mathrm{i}}+\sum \mathrm{P}_{\mathrm{Ri}} \mathrm{R}_{\mathrm{i}}$ is the total value of good and bad outputs and $\gamma=\sum \mathrm{P}_{\mathrm{Xi}} \mathrm{X}_{\mathrm{i}}$ are total input costs. Thus, productivity can be measured as output minus input growth, where outputs are weighted as their share in the total value of outputs and inputs are weighted with their share in total input costs. 


\section{APPENDIX 2}

1. In this study an aggregate economy composite output is considered, namely GDP, denoted as Y, along three bad outputs, $\mathrm{R}=\left(\mathrm{R}_{1}, \mathrm{R}_{2}, \mathrm{R}_{3}\right), \mathrm{CO}_{2}, \mathrm{NO}_{\mathrm{X}}$ and $\mathrm{SO}_{\mathrm{X}}$ emissions. Inputs are labour, $\mathrm{L}$, along with services from produced capital, $\mathrm{K}$, and - in the extended measure - services from the natural capital stock, $\mathrm{S}$. The wage rate is denoted by $\mathrm{w}, u_{K}$ is the user cost of produced capital and $u_{S}$ is the user cost of natural capital, which for non-renewable resources can be shown to correspond to their unit rent under profitmaximising extraction over time (Brandt et al., 2013).

2. The traditional MFP growth measure is a special case of equation (A1.14) in the main text with only one good output, GDP, no bad outputs and only labour and (produced) physical capital as inputs.

$\frac{d \ln M F P}{d t} \equiv \frac{d \ln H^{S}}{d t}=\frac{d \ln Y}{d t}-\left(\frac{w L}{\gamma^{\prime}} \frac{d \ln L}{d t}+\frac{u_{K} K}{\gamma^{\prime}} \frac{d \ln K}{d t}\right)=\frac{d \ln Y}{d t}-\frac{d \ln Z}{d t}$

3. where the suffix $\mathrm{S}$ is used to make clear that this is a special case of the more general transformation function with only one (good) output and two inputs. Note that the weight of the good output becomes 1, when there are no other good or bad outputs. Total resource costs are defined by $\gamma^{\prime} \equiv \mathrm{wL}+\mathrm{u}_{\mathrm{K}} \mathrm{K}$. The shorthand $\frac{\mathrm{dlnZ}}{\mathrm{dt}}$ is used to capture the combined rate of growth of inputs, weighted with their cost share. In the extended framework with natural capital, costs are considered to be larger, including also the costs of services from natural capital $\gamma \equiv w L+u_{K} K+\sum_{i} u_{S_{i}} S_{i}$. The cost shares of both labour and capital will have to be scaled down to reflect the increase in total costs, when the traditional measure is adjusted to include natural capital. Comparing $\gamma$ and $\gamma^{\prime}$ yields $\frac{\gamma^{\prime}}{\gamma}=1-\sum_{\mathrm{i}} \frac{\mathrm{u}_{\mathrm{s}_{\mathrm{i}}} \mathrm{s}_{\mathrm{i}}}{\gamma}$. Equation (A1.14) can then be re-written as:

$\frac{d \ln H}{d t}=\left(\frac{P_{Y i} Y_{i}}{\rho}-1\right) \frac{d \ln Y}{d t}+\sum_{i} \frac{P_{R_{i}} R_{i}}{\rho} \frac{d \ln R_{i}}{d t}+\frac{d \ln Y}{d t}-\frac{\gamma^{\prime}}{\gamma}\left(\frac{w L}{\gamma^{\prime}} \frac{d \ln L}{d t}+\frac{u_{K} K}{\gamma^{\prime}} \frac{d \ln K}{d t}\right)-\sum_{i} \frac{u_{S_{i}} S_{i}}{\gamma} \frac{d \ln S_{i}}{d t}$

$\frac{d \ln G M F P}{d t}=\frac{d \ln M F P}{d t}-\sum_{i} \frac{P_{R_{i}} R_{i}}{\rho}\left(\frac{d \ln Y}{d t}-\frac{d \ln R_{i}}{d t}\right)+\left(1-\frac{\gamma^{\prime}}{\gamma}\right) \frac{d \ln Z}{d t}-\sum_{i} \frac{u_{S_{i}} S_{i}}{\gamma} \frac{d \ln S_{i}}{d t}$

$\frac{d \ln G M F P}{d t}=\frac{d \ln M F P}{d t}-\sum_{i} \frac{P_{R_{i}} R_{i}}{\rho}\left(\frac{d \ln Y}{d t}-\frac{d \ln R_{i}}{d t}\right)+\sum_{i} \frac{u_{S_{i}} S_{i}}{\gamma}\left(\frac{d \ln Z}{d t}-\frac{d \ln S_{i}}{d t}\right)$

where the share of natural capital in total costs and the share of bad output in the value of effective output are calculated as average of two consecutive time periods, following a Törnqvist index approach to measure TFP growth (see Diewert, 1976). Defining $P_{R} R \equiv \sum_{i} P_{R_{i}} R_{i}$, where $\frac{d \ln R}{d t}=\sum_{i} \frac{P_{R_{i}} R_{i}}{P_{R} R} \frac{d \ln R_{i}}{d t}$ and $\mathrm{u}_{\mathrm{S}} \mathrm{S} \equiv \sum_{\mathrm{i}} \mathrm{u}_{\mathrm{S}_{\mathrm{i}}} \mathrm{S}_{\mathrm{i}}$, where $\frac{\mathrm{dln} \mathrm{S}}{\mathrm{dt}}=\sum_{\mathrm{i}} \frac{\mathrm{u}_{\mathrm{S}_{\mathrm{i}}} \mathrm{S}_{\mathrm{i}}}{\mathrm{u}_{\mathrm{S}} \mathrm{S}} \frac{\mathrm{dln} \mathrm{S}_{\mathrm{i}}}{\mathrm{dt}}$, equation (A2.2) can be simplified to read:

$\frac{d \ln G M F P}{d t}=\frac{d \ln M F P}{d t}+\frac{u_{S} S}{\gamma}\left(\frac{d \ln Z}{d t}-\frac{d \ln S}{d t}\right)-\frac{\mathrm{P}_{\mathrm{R}} \mathrm{R}}{\rho}\left(\frac{d \ln Y}{d t}-\frac{d \ln R}{d t}\right)$

4. In countries where data on the user costs of capital is difficult to retrieve, MFP growth estimates are based on the assumption of constant returns to scale and perfect competition. In that case total input costs are equal to GDP and the capital share is calculated as the residual of GDP after deducting labour costs $u_{K}^{\prime} K=P_{Y} Y-w L$. In these cases, any existing rents of natural resources are statistically allocated to 
produced capital K. Consequently, the cost share of capital is overstated if indeed some of this income accrues to natural capital instead. This implies that the user cost in these cases composed of two parts, the true user cost of produced capital and the user cost of natural capital: $u_{K}^{\prime} K=u_{K} K+\sum_{i} u_{S_{i}} S_{i}=P_{Y} Y-w L$. Equation (A.14) can then be re-written as

$$
\begin{aligned}
& \frac{d \ln H}{d t}=\left(\frac{P_{Y i} Y_{i}}{\rho}\right) \frac{d \ln Y}{d t}+\sum_{i} \frac{P_{R_{i}} R_{i}}{\rho} \frac{d \ln R_{i}}{d t}-\left(\frac{w L}{\gamma} \frac{d \ln L}{d t}+\frac{u_{K} K}{\gamma} \frac{d \ln K}{d t}\right)-\sum_{i} \frac{u_{S_{i}} S_{i}}{\gamma} \frac{d \ln S_{i}}{d t} \\
& \frac{d \ln H}{d t}=\left(\frac{P_{Y i} Y_{i}}{\rho}-1\right) \frac{d \ln Y}{d t}+\sum_{i} \frac{P_{R_{i}} R_{i}}{\rho} \frac{d \ln R_{i}}{d t}+\frac{d \ln Y}{d t}-\left(\frac{w L}{\gamma} \frac{d \ln L}{d t}+\frac{u_{K}^{\prime} K}{\gamma} \frac{d \ln K}{d t}+\right) \\
& +\sum_{i} \frac{u_{S_{i}} S_{i}}{\gamma} \frac{d \ln K}{d t}-\sum_{i} \frac{u_{S_{i}} S_{i}}{\gamma} \frac{d \ln S_{i}}{d t} \\
& \frac{d \ln H}{d t}=\frac{d \ln M F P}{d t}-\sum_{i} \frac{P_{R_{i}} R_{i}}{\rho}\left(\frac{d \ln Y}{d t}-\frac{d \ln R_{i}}{d t}\right)+\sum_{i} \frac{u_{S_{i}} S_{i}}{\gamma}\left(\frac{d \ln K}{d t}-\frac{d \ln S_{i}}{d t}\right)
\end{aligned}
$$

5. Which can be simplified to read as:

$$
\frac{d \ln G M F P}{d t}=\frac{d \ln M F P}{d t}+\frac{u_{S} S}{\gamma}\left(\frac{d \ln K}{d t}-\frac{d \ln S}{d t}\right)-\frac{\mathrm{P}_{\mathrm{R}} \mathrm{R}}{\rho}\left(\frac{d \ln Y}{d t}-\frac{d \ln R}{d t}\right)
$$




\section{APPENDIX 3}

\section{Estimation framework}

1. Transforming a simplified version of equation (2) with only one good output, $\mathrm{Y}$, and one bad output, $\mathrm{R}$, it is possible to derive an equation, with which the elasticity of the transformation function - and hence the revenue share of good and bad outputs - can be estimated:

$\frac{d \ln H}{d t}=\frac{P_{Y} Y}{\rho} \frac{d \ln Y}{d t}+\frac{P_{R} R}{\rho} \frac{d \ln R}{d t}-\sum_{i} \frac{P_{X i} X_{i}}{\gamma} \frac{d \ln X_{i}}{d t}$

Remembering that $\frac{P_{Y} Y}{\rho}+\frac{P_{R} R}{\rho}=1$, so that $\frac{P_{R} R}{P_{Y} Y}=\frac{\rho}{P_{Y} Y}-1$ and re-arranging (A3.1) yields:

$\frac{d \ln Y}{d t}=\frac{\rho}{P_{Y} Y} * \frac{d \ln H}{d t}+\frac{\rho}{P_{Y} Y} * \frac{d \ln Z}{d t}+\left(1-\frac{\rho}{P_{Y} Y}\right) *\left(\frac{d \ln R}{d t}\right)$

Where $\frac{d \ln Z}{d t}=\sum_{i} \frac{P_{X i} X_{i}}{\gamma} \frac{d \ln X_{i}}{d t}$. From (A3.2) we derive our fixed-effect estimation equation

$\hat{Y}_{i t}=\alpha_{0 i}+\alpha_{1} * \hat{Z}_{i t}+\alpha_{2} * \hat{R}_{i t}+\varepsilon_{i t}$

where $\alpha_{0 i}$ is a country specific intercept and $\varepsilon$ is an error term.

2. The coefficient $\alpha_{2}$ can be used to calculate the elasticity of $\mathrm{R}$ with respect to the transformation function and the shadow price as follows:

$\alpha_{2}=1-\frac{\rho}{P_{Y} Y}=\frac{P_{Y} Y}{P_{Y} Y}-\frac{P_{Y} Y+P_{R} R}{P_{Y} Y}=-\frac{P_{R} R}{P_{Y} Y}$

Starting from equation (A.1.10), extending by $\mathrm{P}_{\mathrm{Y}} \mathrm{Y}$ and reformulating yields the expression for the elasticity of R:

$\varepsilon_{H R_{i}}=-\frac{P_{R} R}{\rho}=\frac{-\frac{P_{R} R}{P_{Y} Y}}{\left(\frac{\rho}{P_{Y} Y}\right)}=\frac{\alpha_{2}}{\frac{P_{Y} Y+P_{R} R}{P_{Y} Y}}=\frac{\alpha_{2}}{1+\frac{P_{R} R}{P_{Y} Y}}=\frac{\alpha_{2}}{1-\alpha_{2}}$

Reformulation of equation (A.3.4) yields the formula for the shadow price:

$P_{R}=-\alpha_{2} * \frac{P_{Y} Y}{R}$ 


\section{APPENDIX 4}

1. To infer how average GDP growth would have to change, given a specific decrease in the average growth rate of bad output, compare productivity growth, $\frac{\overline{\frac{d \operatorname{lnH}}{d t}}}{\mathrm{~K}}$, rates in period I and II, remembering that average productivity growth, and input growth, $\overline{\overline{X_{\mathrm{K}}}}$, for all inputs $\mathrm{i}$ across the two periods $\mathrm{K}=\mathrm{I}$,II.

$$
\overline{\bar{Y}_{I}}-\overline{\widehat{Y_{I I}}}=\frac{\varepsilon_{H R}}{\varepsilon_{H Y}}\left(\overline{\overline{R_{I}}}-\overline{\widehat{R_{I I}}}\right)
$$

2. To infer how average productivity growth would have to change, given a specific decrease in the average growth rate of bad output, compare productivity growth, $\frac{\overline{\mathrm{dn} H}}{\mathrm{dt}} \mathrm{I}$, rates in period I and II, remembering that output and input growth would stay the same

$\frac{\overline{d \overline{\operatorname{lnH}}}}{d t_{I}}-\frac{\overline{d \overline{\operatorname{lnH}}}}{d t}=-\varepsilon_{R Y}\left(\overline{\bar{R}_{I}}-\overline{\widehat{R}_{I I}}\right)$ 
ECO/WKP(2014)50

\section{BIBLIOGRAPHY}

Aigner, D.J. and S.F. Chu (1968), "On estimating the industry production function", American Economic Review, Vol. 13, pp. 826- 839.

Atkinson, S.E. and J.H. Dorfman (2005), "Bayesian measurement of productivity and efficiency in the presence of undesirable outputs: crediting electric utilities for reducing air pollution", Journal of Econometrics, Vol. 126, pp. 445-468.

Australian Productivity Commission (2011), Carbon Emission Policies in Key Economies, Productivity Commission Research Report, Canberra.

Brandt, N., P. Schreyer and V. Zipperer (2013), "Productivity measurement with natural capital", $O E C D$ Economics Department Working Papers, No. 1092, OECD Publishing.

Coggins, J. S. and J. R. Swinton (1996), "The Price of Pollution: A Dual Approach to Valuing $\mathrm{SO}_{2}$ Allowances", Journal of Environmental Economics and Management, Vol. 30, pp. 58-72.

Coelli, T. (2002), "On the Econometric Estimation of the Distance Function Representation of a Production Technology", Working Paper, Université Catholique de Louvain, Center for Operations Research and Economics, May 2002.

Cornwell, C., P. Schmidt, and R. Sickles (1990), "Production frontiers with cross-sectional and time-series variation in efficiency levels", Journal of Econometrics, Vol. 46, pp. 185-200.

Cuesta, R., C.A. Knox Lovell and J. Zofio (2009), "Environmental efficiency measurement with translog distance functions: A parametric approach", Ecological Economics, Vol. 68, pp. 2232-2242.

Färe, R., S. Grosskopf, C. A. Knox Lovell and S. Yaisawarng (1993), "Derivation of Shadow Prices for Undesirable Outputs: A Distance Function Approach", The Review of Economics and Statistics, Vol. 75(2), pp. 374-380.

Färe, R., S. Grosskopf, D.-W. Noh and W. Weber (2005), "Characteristics of a polluting technology: theory and practice", Journal of Econometrics, Vol. 126, pp. 469-492.

Färe, R. and Primont (2005), "Multi-Output Production and Technology: Theory and Applications". Kluwer, Norwell, Massachussetts.

Färe, R. and S. Grosskopf (1990), “A Distance Function Approach to Measuring Price Efficiency”, Journal of Public Economics, Vol. 43, pp. 123-126.

Gollop, F. and G.P. Swinand (2001), "Total Resource Productivity. Accounting for Changing Environmental Quality", in Hulten, C.R. et al. (eds.) New Developments in Productivity Analysis, pp. $587-608$.

Hailu, A. and T.S. Veeman (2000), "Environmentally sensitive productivity analysis of the Canadian pulp and paper industry, 1959-1994: an input distance function approach", Journal of Environmental Economics and Management, Vol. 40 (3), pp. 251-274.

IEA (2011), World Energy Outlook 2011, OECD Publishing, Paris. 
Keilbach, M. (1995), "Estimation of the Value of the Marginal Product of Emissions in a Country where Emissions Output is Regulated - An Empirical Study", Environmental and Resource Economics, Vol. 5, pp. 305-319.

Kwon, O.S. and W-C. Yun (1999), "Estimation of the marginal abatement costs of airborne pollutants in Korea'spower generation sector", Energy Economics, Vol. 21 (6), pp. 547-560.

Lee, J.-D., J.-B. Park and T.-Y. Kim (2002), "Estimation of the Shadow Prices of Pollutants with Production/Environment Inefficiency taken into Account: a Nonparametric Directional Distance Function Approach", Journal of Environmental Management, Vol. 64, pp. 365-375.

Maradan, D. and A. Vassiliev (2005), "Marginal Costs of Carbon Dioxide Abatement: Empirical Evidence from Cross-Country Analysis", Schweizerische Zeitschrift für Volkswirtschaft und Statistik, Vol. 141, pp. 377-410.

Mekaroonreung, M. and A. L. Johnson (2012), "Estimating the Shadow Prices of $\mathrm{SO}_{2}$ and $\mathrm{NO}_{\mathrm{X}}$ for U.S. Coal Power Plants: A Convex Nonparametric Least Squares Approach", Energy Economics, Vol. 34, pp. 723-732.

Muller, N., R. Mendelsohn and W. Nordhaus (2011), "Environmental Accounting for Pollution in the United States Economy", American Economic Review, Vol. 101, pp. 1649-1675.

OECD (2001), Measuring Productivity, OECD Publishing, Paris.

OECD (2009), Manual on Capital Stock Measurement, OECD Publishing, Paris.

OECD (2013a), Taxing Energy Use: A Graphical Analysis, OECD Publishing. http://dx.doi.org/10.1787/9789264183933-en

OECD (2013b), Effective Carbon Prices, OECD Publishing. http://dx.doi.org/10.1787/9789264196964-en

Pindyck, R. S. (2013), "Climate change policy: What do the models tell us?", NBER Working Paper Series 19244, National Bureau of Economic Research, Cambridge Massachusetts.

Pittman, R. W (1983), "Multilateral Productivity Comparisons with Undesirable Outputs", The Economics Journal, Vol. 93, No. 372, pp. 883-891.

Rezek, J. and B. F. Blair (2005), “Abatement Cost Heterogeneity in Phase I Electric Utilities", Contemporary Economic Policy, Vol. 23(3), pp. 324-340.

Rezek, J. P. and R. C. Campbell (2007), "Cost Estimates for Multiple Pollutants: A Maximum Entropy Approach”, Energy Economics, Vol. 29, pp. 503-519.

Rezek, J.P., and R.K. Perrin (2004), "Environmentally-adjusted productivity in the Great Plains", Journal of Agricultural and Resource Economics, Vol. 29 (2), pp. 346- 369.

Shephard, R. W. (1970), "Theory of Cost and Production Functions", Princeton University Press, Princeton.

Tol, R. S. J. (2005), "The Marginal Damage Costs of Carbon Dioxide Emissions: an Assessment of the Uncertainties”, Energy Policy, Vol. 33, pp. 2064-2074.

Tol, R. S. J. (2008), “The Social Cost of Carbon: Trends, Outliers and Catastrophes”, Economics: The Open-Access, Open-Assessment E-Journal, Vol. 2(25).

Vouvaki, D. and A. Xepapadeas (2008), "Total factor productivity growth when factors of production generate environmental externalities", MPRA 10237. http://mpra.ub.uni-muenchen.de/10237/ 
ECO/WKP(2014)50

\section{WORKING PAPERS}

The full series of Economics Department Working Papers can be consulted at www.oecd.org/eco/workingpapers

1153. Reducing income inequality and poverty and promoting social mobility in Korea (July 2014) by Randall S. Jones and Satoshi Urasawa

1152. Fostering a creative economy to drive Korean growth (July 2014) by Randall S. Jones

1151. Economic uncertainties and their impact on activity in Greece compared with Ireland and Portugal

(July 2014) by Jan-David Schneider and Claude Giorno

1150. $\quad$ Workplace stress in the United States: issues and policies (July 2014) by Michael Darden

1149. Taxing the rent of non-renewable resource sectors: a theoretical note (July 2014) by Julien Daubanes and Saraly Andrade de Sá

1148. Health, work and working conditions: a review of the European economic literature (July 2014) by Thomas Barnay

1147. Making the best of new energy resources in the United States (July 2014) by Douglas Sutherland

1146. Improving well-being in the United States (July 2014) by Aida Caldera Sánchez, Patrick Lenain and Sarah Fléche

1145. Deconstructing Canada's housing markets: finance, affordability and urban sprawl (July 2014) by Calista Cheung

Restructurer les marchés canadiens du logement: financements, accessibilité financière et étalement urbain

(Juillet 2014) par Calista Cheung

1144. Women's role in the Swiss economy

(July 2014) by Richard Dutu

Le rôle des femmes dans l'économie suisse

(Juillet 2014) par Richard Dutu

1143. Overcoming skills shortages in Canada

(July 2014) by David Carey

Combler les pénuries de compétences au Canada

(Juillet 2014) par David Carey

1142. Trade patterns in the 2060 world economy

(July 2014) by Jean Chateau, Lionel Fontagné, Jean Fouré, Åsa Johansson and Eduardo Olaberria

1141. The Demand for Skills 1995-2008: A global chain perspective

(July 2014) by Bart Los, Marcel P. Timmer and Gaaitzen J. De Vries 
1140. International migration: The relationship with economic and policy factors in the home and destination country

(July 2014) by Ben Westmore

1139. Gross earning inequalities in OECD countries and major non-member economies: determinants and future scenarios

(July 2014) by Henrik Braconier and Jenifer Valenzuela Ruiz

1136. Long-term patterns of trade and specialisation

(July 2014) by Asa Johansson and Eduardo Olaberria

1135. Consequences of climate change damages for economic growth - a dynamic quantitative assessment

(July 2014) by Rob Dellink, Elisa Lanzi, Jean Chateau, Francesco Bosello, Ramiro Parrado and Kelly de Bruin

1134. Comparing the robustness of PAYG pension schemes

(July 2014) by Falilou Fall

1133. Overcoming vulnerabilities of pension systems

(July 2014) by Falilou Fall and Debbie Bloch

1132. Overcoming vulnerabilities of health care systems

(July 2014) by Mauro Pisu

1131. Overcoming vulnerability of unemployment insurance schemes

(July 2014) by Jon Pareliussen

1130. Vulnerability of social institutions: Lessons from the recent crisis and historical episodes (July 2014) by Falilou Fall, Mauro Pisu, Jon Pareliussen and Debbie Bloch

1129. An update of the OECD international trade equations (June 2014) by Myriam Morin and Cyrille Schwellnus

1128. What explains the volume and composition of trade? Industrial evidence from a panel of countries

(June 2014) by Asa Johansson, Przemyslaw Kowalski, Eduardo Olaberria and Dario Pellegrino

1127. Do resources flow to patenting firms: cross-country evidence from firm level data

(June 2014) by Dan Andrews, Chiara Criscuolo and Carlo Menon

1126. Macroprudential policy tools in Norway: Strengthening financial system resilience

(June 2014) by Yosuke Jin, Patrick Lenain and Paul O’Brien

1125. Strengthening competition in Poland

(June 2014) by Balász Égert and Antoine Goujard

1124. Making the labour market work better in Poland

(June 2014) by Hervé Boulhol 